\title{
Multi-directional random wave interaction with an array of cylinders
}

\author{
Ji, Xinran; Liu, Shuxue; Bingham, Harry B.; Li, Jinxuan
}

Published in:

Ocean Engineering

Link to article, DOI:

10.1016/j.oceaneng.2015.09.039

Publication date:

2015

Document Version

Peer reviewed version

Link back to DTU Orbit

Citation (APA):

Ji, X., Liu, S., Bingham, H. B., \& Li, J. (2015). Multi-directional random wave interaction with an array of cylinders. Ocean Engineering, 110, 62-77. https://doi.org/10.1016/j.oceaneng.2015.09.039

\section{General rights}

Copyright and moral rights for the publications made accessible in the public portal are retained by the authors and/or other copyright owners and it is a condition of accessing publications that users recognise and abide by the legal requirements associated with these rights.

- Users may download and print one copy of any publication from the public portal for the purpose of private study or research.

- You may not further distribute the material or use it for any profit-making activity or commercial gain

- You may freely distribute the URL identifying the publication in the public portal

If you believe that this document breaches copyright please contact us providing details, and we will remove access to the work immediately and investigate your claim. 


\title{
Multi-directional random wave interaction with an array of cylinders
}

\author{
Xinran $\mathrm{Ji}^{1,2}$, Shuxue Liu ${ }^{1}$, Harry B. Bingham ${ }^{2}$, Jinxuan $\mathrm{Li}^{1}$ \\ 1. State Key Laboratory of Coastal and Offshore Engineering, Dalian University of Technology, Dalian 116024, \\ China \\ 2. Department of Mechanical Engineering, Technical University of Denmark, DK-2800 Kgs. Lyngby, Denmark
}

\begin{abstract}
Based on the linear theory of wave interaction with an array of circular bottom-mounted vertical cylinders, systematic calculations are made to investigate the effects of the wave directionality on wave loads in short-crested seas. The multi-directional waves are specified using a discrete form of the Mitsuyasu-type spreading function. The time series of multi-directional wave loads, including both the wave run-up and the wave force, can be simulated. The effect of wave directionality on the wave run-up and wave loading on the cylinders is investigated. For multi-directional random waves, as the distribution of wave spreading becomes wider, the wave run-up at some points around the cylinders is found to increase. This suggests that multi-directional wave run-up tends to be larger than unidirectional wave run-up. In addition, the wave directionality has a significant influence on the transverse force. The biggest transverse force is found to occur on the rear cylinder rather than the front one. This is quite different from the results in unidirectional waves and should be paid much more attention in the design of offshore structures. At last, the possibility of the near-trapping under the multi-directional random waves is investigated. It is found that the near-trapping also occurs for multi-directional wave conditions.
\end{abstract}

Key words: Multi-directional random wave; cylinders; wave run-up; wave force; wave directionality; near-trapping 


\begin{tabular}{|c|c|}
\hline Nomenclature & \\
\hline$a$ & cylinder radius \\
\hline$A$ & wave amplitude for calculated waves \\
\hline$A_{0}$ & incident wave amplitude \\
\hline$d$ & water depth \\
\hline$D$ & cylinder diameter \\
\hline$f_{x}$ & normal wave force \\
\hline$f_{y}$ & transverse wave force \\
\hline$F_{x}$ & non-dimensional significant normal wave force \\
\hline$F_{y}$ & non-dimensional significant transverse wave force \\
\hline$G(f, \theta)$ & directional spreading function \\
\hline$H_{1 / 3}$ & significant wave height \\
\hline$i$ & imaginary unit, $i^{2}=-1$ \\
\hline$k$ & wave number \\
\hline$L$ & distance between two adjacent cylinders \\
\hline$m_{0}$ & zeroth moment of wave spectrum \\
\hline$N$ & number of cylinders \\
\hline$k$ & wave number \\
\hline$R$ & non- dimensional wave run-up \\
\hline$s$ & directional spreading parameter \\
\hline$S(f)$ & wave frequency spectrum \\
\hline$S(f, \theta)$ & wave directional spectrum \\
\hline$T_{1 / 3}$ & significant wave period \\
\hline$T_{p}$ & peak wave period \\
\hline$\alpha$ & angle around cylinder \\
\hline$\beta$ & angle for the incident wave \\
\hline$\gamma$ & peak enhancement factor of JONSWAP spectrum \\
\hline$\lambda$ & wave length \\
\hline$\sigma_{\theta}$ & standard deviation of directional spreading \\
\hline$\omega$ & wave angular frequency \\
\hline
\end{tabular}




\section{Introduction}

Circular cylinders are often used in offshore engineering and many offshore structures are comprised of arrays of cylinders. Examples include bridges, wind turbine foundations, offshore platforms and floating airports. In ocean engineering design, wave loading is an important factor. There are two regimes for calculating the wave loads on a cylinder, depending on the slenderness parameters $D / \lambda$, with $D$ is the diameter of a cylinder and $\lambda$ is the wave length. If $D / \lambda>0.15$, wave diffraction is important and should be considered, otherwise it can be ignored.

For wave loads on a large cylinder, a superposition eigenfunction expansion method was used by MacCamy and Fuchs (1954) to obtain a linear solution, based on the assumption that the incident wave has a small steepness. For the case of waves acting upon an array of cylinders, the effect of a given cylinder on the incident wave will produce a scattered wave which will in turn be scattered by adjacent cylinders. Thus the computation of the velocity potential must account for the diffraction of the incident wave field by each body and the multiple scattering from other bodies. An exact solution for the diffraction of linear water waves by arrays of bottom-mounted, vertical circular cylinders was first given by Spring and Monkmeyer (1974) using a direct matrix method. It represented an extension of the single cylinder case presented by MacCamy and Fuchs (1954). Further, an approximate solution to this problem was given by McIver and Evans (1984) in which they assumed that the cylinders were widely spaced. An accurate algebraic method was developed by Kagemoto and Yue (1986) to calculate the hydrodynamic properties of a system of multiple three-dimensional bodies in water waves. Subsequently, a simplified expression for the velocity potential in the vicinity of a particular cylinder was developed by Linton and Evans (1990) which led to simple formulae for the first-order and mean second-order wave forces on multiple cylinders as well as the free surface profile.

Based on wave tank experiment and numerical methods, a number of researchers have studied wave interaction with an array of cylinders. Ohl et al. (2001a, 2001b) studied regular and irregular wave interaction with an array of cylinders, and a very good agreement between the theory and the laboratory results was found. Ma et al. (2001a, 2001b) studied fully nonlinear wave diffraction around a pair of fixed cylinders in a numerical wave tank based on the finite element method (FEM). A semi-analytical solution was developed by Huang (2004) for second-order wave diffraction by an array of cylinders in monochromatic waves. It was found that at relatively high frequencies, the enhancement of the second-order component in the wave run-up was much more general than on the forces. Wang and $\mathrm{Wu}$ (2010) developed a fully nonlinear numerical wave tank to simulate three-dimensional waves and wave-structure interactions by the finite element method. The effect of the tank wall on waves and forces was investigated, and the nonlinear features of waves and 
forces were also discussed. Govaere et al. (1999, 2001) derived linear wave transformation due to the presence of an impermeable cylindrical pile protected by a series of submerged permeable structures and wave loads on the pile were studied. Zhao et al. (2010) investigated the diffraction of waves by an array of porous circular cylinders based on the linear wave theory and model test.

On the other hand, some researchers focused on the phenomenon of near trapping. Maniar and Newman (1997) considered a long array of cylinders (up to 101 cylinders). They found that when the wave number was close to the nearly trapped mode, a very large hydrodynamic force could arise on the cylinders in the middle of the array. Evans and Porter $(1997,1999)$ found that for the wave forces on circular arrays of four, five and six cylinders, the near trapping phenomenon also existed. Maleniča et al. (1999) further showed that similar behavior could occur for the second-order result. Duclos and Clèment (2004) extended this work to consider arrays of unevenly spaced cylinders, displaced randomly from a regular array according to a disordering parameter. They focused on two effects of this spacing irregularity, reduction of peak forces associated with the trapped mode phenomena, and regularization of the transmission coefficient for waves propagating through the arrays. Kagemoto et al. (2013, 2014) studied the second-order resonance among an array of two rows of cylinders by experiment and theoretical calculation. This work found that large free-surface displacements could be induced for special wave conditions.

However, most of the research associated with wave interaction with arrays of cylinders has been focused on unidirectional waves. But in reality, sea waves are multi-directional waves. In multi-directional sea condition, the wave directionality could lead to quite different wave-structure interaction results compared with the unidirectional wave fields. Yu et al. (1996) investigated the wave force due to multi-directional random waves on a small vertical cylinder by experiment. The variation of various hydrodynamic coefficients with $\mathrm{KC}$ number and wave directional spreading was investigated. Lee et al. (2007) used a numerical model to predict the interaction of multi-directional random surface waves with rectangular submarine pits. Liu et al. (2010, 2012) solved the modified Boussinesq equations based on a finite element model with unstructured triangular elements, and considered the effects of wave directionality on the wave run-up on a group of cylinders. Ji et al. (2013, 2014, and 2015) systematically investigated the multi-directional random wave forces and run-up on a large cylinder by experimental and numerical methods. It was found that a small directional spreading parameter (high directionality), gives rise to a large transverse force which should not be ignored. The dynamic response of a mini-Tension Leg Platform under multi-directional wave conditions was studied by Niedzwecki et al. (2001). Li et al. (2012, 2014) studied the interaction of multi-directional focused waves with a vertical cylinder by experiment. The effect of 
a multi-directional focused wave on wave loads was investigated. The interaction of waves with porous circular cylinder and cylinders were studied theoretically by Silva et al. (2002, 2003), and then it was extended to unidirectional and multi-directional waves, it was found that as the spectrum broadens in frequency and angle, the modulation around the structure damps faster.

In the present paper, the superposition method is used to study the multi-directional random wave loads on an array of large-scale bottom-mounted vertical cylinders. Linton and Evans' method is used as the transfer function, which is combined with multi-directional random waves to predict the interactions with arrays of cylinders. Considering that there are rather few references in the literature about real sea wave loads on an array of cylinders, our main concern in this paper is focused on the effect of the wave directionality on the multi-directional wave run-up and the force loading on a cylinder array. The goal is that these results will provide a reference to improve the design of offshore structures. 


\section{The model of multi-directional random wave loads on cylinders}

\subsection{Wave interaction with cylinders in regular wave conditions}

Under the assumption of linear wave theory, the incident wave velocity potential can be described as:

$$
\Phi(x, y, z, t)=\operatorname{Re}\left\{-\frac{i g A}{\omega} \frac{\cosh (z+d)}{\cosh k d} \phi_{i n c}(x, y) e^{-i \omega t}\right\}
$$

where $A$ represents the amplitude of the incident wave, $d$ the water depth, and the wave number $k$ and the wave frequency $\omega$ should satisfy the dispersion relation

$$
\omega^{2}=g k \tanh k d
$$

in which $g$ is the gravitational acceleration.

A sketch of the situation is shown in Fig.1, which shows an array of bottom-mounted vertical cylinders with an incident wave with an angle $\beta$. We assume that there are $N(N \geq 1)$ fixed vertical circular cylinders, so $N+1$ coordinate systems will be used: $(r, \theta)$ are polar coordinates in the $(x, y)$-plane centered at the global origin whilst $\left(r_{j}, \theta_{j}\right), j=1, \ldots, N$ are polar coordinates centered at $\left(x_{j}, y_{i}\right)$ which is the centre of the $j$ th cylinder. The various parameters relating to the relative positions and sizes of the $N$ cylinders are also shown in Fig.1.

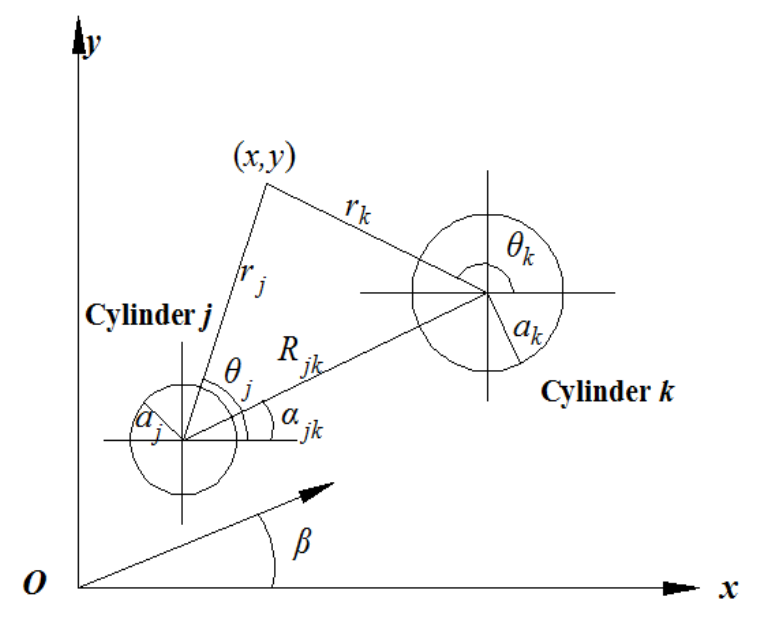

Fig.1 Sketch of the wave interaction with array of bottom-mounted vertical cylinders

In the global coordinate, the incident wave can be written as

$$
\phi_{i n c}=e^{i k(x \cos \beta+y \sin \beta)}=e^{i k r \cos (\theta-\beta)}
$$

while in the $\left(r_{j}, \theta_{j}\right)$ coordinates, it can be expressed as 


$$
\phi_{i n c}=I_{j} e^{i k r_{j} \cos \left(\theta_{j}-\beta\right)}=I_{j} \sum_{n=-\infty}^{\infty} J_{n}\left(k r_{j}\right) e^{-i n \theta_{j}} e^{i n\left(\frac{\pi}{2}+\beta\right)}
$$

where $I_{j}=e^{i k\left(x_{j} \cos \beta+y_{j} \sin \beta\right)}$ is a phase factor associated with cylinder $j$.

The radiating wave emanating from cylinder $j$ is

$$
\phi_{d}^{j}=\sum_{n=-\infty}^{\infty} A_{n}^{j} C_{n}^{j} H_{n}\left(k r_{j}\right) e^{i n \theta_{j}}
$$

where $A_{n}^{j}$ are unknown coefficients, $C_{n}^{j}=J_{n}^{\prime}\left(k a_{j}\right) / H_{n}^{\prime}\left(k a_{j}\right)$ and $H_{n}(x)=J_{n}(x)+i Y_{n}(x)$.

The total potential can be written as

$$
\phi=\phi_{i n c}+\sum_{j=1}^{N} \phi_{d}^{j}=e^{i k r \cos (\theta-\beta)}+\sum_{j=1}^{N} \sum_{n=-\infty}^{\infty} A_{n}^{j} C_{n}^{j} H_{n}\left(k r_{j}\right) e^{i n \theta_{j}}
$$

and Eq.(6) should satisfy the boundary conditions for each cylinder

$$
\frac{\partial \phi}{\partial r_{k}}=0 \quad\left(r_{k}=a_{k}, k=1, \ldots, N\right)
$$

Using Graf's addition theorem for Bessel functions

$$
H_{n}\left(k r_{j}\right) e^{i n \theta_{j}}=\sum_{m=-\infty}^{\infty} H_{n+m}\left(k R_{j k}\right) J_{m}\left(k r_{k}\right) e^{i\left(m \alpha_{j k}+n \alpha_{j k}\right)} e^{-i m \theta_{k}} \quad\left(r_{k}<R_{j k}\right)
$$

Then the following infinite system of equations can be obtained

$$
A_{m}^{k}+\sum_{\substack{j=1 \\ j \neq k}}^{N} \sum_{n=-\infty}^{\infty} A_{n}^{j} C_{n}^{j} e^{i(n-m) \alpha_{j k}} H_{n-m}\left(k R_{j k}\right)=-I_{k} e^{i m(\pi / 2-\beta)}
$$

In order to solve for the coefficients $A_{n}^{j}$, the superposition number $n$ is truncated at $M$, and the infinite sum in Eq. (9) is turned into $N \times(2 M+1)$ equations with $N \times(2 M+1)$ unknowns $A_{n}^{j}$.

The wave potential near cylinder $k$ shown in Fig. 1 is

$$
\begin{aligned}
\phi\left(r_{k}, \theta_{k}\right) & =\sum_{n=-\infty}^{\infty}\left[I_{k} J_{n}\left(k r_{k}\right) e^{i n\left(\pi / 2-\theta_{j}+\beta\right)}+A_{n}^{k} Z_{n}^{k} H_{n}\left(k r_{k}\right) e^{i n \theta_{k}}\right] \\
& +\sum_{\substack{j=1 \\
j \neq k}}^{N} \sum_{n=-\infty}^{\infty} A_{n}^{k} C_{n}^{k} \sum_{m=-\infty}^{\infty} H_{n+m}\left(k R_{j k}\right) J_{m}\left(k R_{j k}\right) e^{i(m+n) \alpha_{j k}} e^{-i m\left(\pi-\theta_{k}\right)} \quad\left(r_{k}<R_{j k}\right)
\end{aligned}
$$

For the final term in Eq.(10), replacing $m$ by $-m$ allows us to write this term as 


$$
\sum_{m=-\infty}^{\infty}\left[\sum_{\substack{j=1 \\ j \neq k}}^{N} \sum_{n=-\infty}^{\infty} A_{n}^{j} C_{n}^{j} H_{n-m}\left(k R_{j k}\right) e^{i(n-m) \alpha_{j k}}\right] J_{m}\left(k r_{k}\right) e^{i m \theta_{k}}
$$

Using Eq. (9), a simple formula for the wave potential is

$$
\phi\left(r_{k}, \theta_{k}\right)=\sum_{n=-\infty}^{\infty} A_{n}^{k}\left[C_{n}^{k} H_{n}\left(k r_{k}\right)-J_{n}\left(k r_{k}\right)\right] e^{i n \theta_{k}} \quad\left(r_{k}<R_{j k}\right)
$$

and the wave potential on cylinder $k$ reduces to

$$
\phi\left(a_{k}, \theta_{k}\right)=-\frac{2 i}{\pi k a_{k}} \sum_{n=-M}^{M} \frac{A_{n}^{k}}{H_{n}^{\prime}\left(k a_{k}\right)} e^{i n \theta_{k}}
$$

The wave force loads on cylinder $k$ can be given by integrating the pressure over the surface of the cylinder

$$
\left\{\begin{array}{c}
f_{x}^{k} \\
f_{y}^{k}
\end{array}\right\}=-\left\{\begin{array}{l}
i \\
1
\end{array}\right\} \frac{2 \rho g A \tanh k d}{k^{2} H_{1}^{\prime}\left(k a_{k}\right)}\left(A_{-1}^{k}\left\{\begin{array}{c}
- \\
+
\end{array}\right\} A_{1}^{k}\right) .
$$

The wave elevation can be written as

$$
\begin{aligned}
& \eta^{\prime}(r, \theta)=\left.A \frac{i \omega}{g} \phi(r, \theta)\right|_{z=0} \\
& =A\left(e^{i k r \mathrm{co} \theta+\beta}+\sum_{j=1}^{N} \sum_{n=-\infty}^{\infty} A_{n}^{j} C_{n}^{j} H_{n}\left(k r_{j} \theta\right)^{i n \theta_{j}} .\right.
\end{aligned}
$$

The wave force and wave elevation for unit wave amplitude can be expressed as

$$
\begin{gathered}
\left\{\begin{array}{c}
T_{f x}^{k} \\
T_{f y}^{k}
\end{array}\right\}=-\left\{\begin{array}{l}
i \\
1
\end{array}\right\} \frac{2 \rho g \tanh k d}{k^{2} H_{1}^{\prime}\left(k a_{k}\right)}\left(A_{-1}^{k}\left\{\begin{array}{l}
- \\
+
\end{array}\right\} A_{1}^{k}\right) \\
T_{\eta}(r, \theta)=e^{i k r \cos (\theta-\beta)}+\sum_{j=1}^{N} \sum_{n=-\infty}^{\infty} A_{n}^{j} C_{n}^{j} H_{n}\left(k r_{j}\right) e^{i n \theta_{j}}
\end{gathered}
$$

\subsection{Wave interaction with cylinders in multi-directional random wave conditions}

To simulate the multi-directional random wave loads on an array of cylinders, the multi-directional random wave is generated by the superposition method. The above solution for regular wave interaction with cylinders can be regarded as a transfer function.

For multi-directional waves, the directional spectrum $S(f, \theta)$ can be written as the product of a frequency spectrum $S(f)$ and a directional spreading function $G(f, \theta)$, i.e.,

$$
S(f, \theta)=S(f) G(f, \theta)
$$

The frequency spectrum used in the paper is the JONSWAP spectrum suggested by Goda (1999): 


$$
S(f)=\beta_{J} H_{1 / 3}^{2} T_{1 / 3}^{-4} f^{-5} \exp \left[-1.25\left(\mathrm{~T}_{p} f\right)^{-4}\right] \cdot \gamma^{\exp \left[-\left(T_{p} f-1\right)^{2} / 2 \sigma^{2}\right]}
$$

where

$$
\begin{aligned}
\beta_{J} & =\frac{0.06238}{0.230+0.0336 \gamma-0.185(1.9+\gamma)^{-1}} \times[1.094-0.01915 \ln \gamma] \\
T_{p} & =\frac{T_{1 / 3}}{1.0-0.132(\gamma+0.2)^{-0.559}} \\
\sigma & = \begin{cases}0.07 & f \leq f_{p} \\
0.09 & f>f_{p}\end{cases}
\end{aligned}
$$

here, $H_{1 / 3}$ and $T_{1 / 3}$ are the significant wave height and the significant period, respectively, $T_{p}$ and $f_{p}$ are the peak period and the corresponding peak frequency, and $\gamma$ is the peak enhancement factor, which takes a value of 3.3 in this paper.

For a multi-directional wave, the total wave energy $m_{0}$ should be consistent with a unidirectional wave. This means that the frequency spectrum and the directional spectrum should satisfy the following equation:

$$
m_{0}=\int_{0}^{\infty} S(f) d f=\int_{0}^{\infty} \int_{\theta_{\min }}^{\theta_{\max }} S(f, \theta) d \theta d f
$$

where $\left[\theta_{\min }, \theta_{\max }\right]$ is the directional distribution range. So, the directional spreading function $G(f, \theta)$ must satisfy:

$$
\int_{\theta_{\min }}^{\theta_{\max }} G(f, \theta) d \theta=1
$$

The Mitsuyasu-type spreading function is adopted here for the directional spreading function, defined by Longuet-Higgins et al. (1963) as

$$
G(f, \theta)=G_{0}(s) \cos ^{2 s}\left(\frac{\theta-\theta_{0}}{2}\right)
$$

where $s$ is the directional spreading parameter. Clearly, the larger the parameter $s$, the wider the directional distribution, $s=\infty$ means the unidirectional waves. $\theta_{0}$ is the principal wave direction, in present paper, $\theta_{0}=0^{\circ}$ is specified. Because Eq. (21) must satisfy the condition of Eq. (20), $G_{0}(s)$ can be solved as follows:

$$
G_{0}(s)=\left[\int_{\theta_{\min }}^{\theta_{\max }} \cos ^{2 s}\left(\frac{\theta-\theta_{0}}{2}\right) d \theta\right]^{-1}
$$

where $\left[\theta_{\min }, \theta_{\max }\right]$ takes $\left[-90^{\circ}, 90^{\circ}\right]$ in the study described in this paper. For convenience, $s$ is taken as independent of the frequency.

For the purpose of numerical applications, the incident wave spectrum must be discretized into a finite number of wave components in order to obtain the incident wave spectrum. An adequate discretization in both frequency and direction is essential to simulate the surface of multi-directional wave. In the present work, the number of component frequencies is denoted by $M_{f}$ while wave direction will be divided into $N_{\theta}$ parts. The frequency range is well-discretized and each frequency band has an equal interval, then the bandwidth $d \omega$ associated with the $m$ th frequency is defined by 


$$
\begin{aligned}
& d \omega=\frac{\omega_{H}-\omega_{L}}{M_{f}} \\
& \bar{\omega}_{m}=\frac{1}{2}\left(\omega_{m}+\omega_{m-1}\right)
\end{aligned}
$$

where, $\omega_{H}$ and $\omega_{L}$ means the maximum and minimum angular frequency of multi-directional random waves. Similarly,

$$
d \theta=\frac{\theta_{\max }-\theta_{\min }}{N_{\theta}}
$$

Several directional wave models can be used for the multi-directional wave simulation. In this paper, the improved single direction per frequency model (Yu et al. 1991) was used. The surface elevation $\eta_{1}(x, y, t)$ at the point $(x, y)$ can be expressed as

$$
\begin{gathered}
\eta_{1}(x, y, t)=\sum_{m=1}^{M_{f}} \sum_{n=1}^{N_{\theta}} \sqrt{2 S\left(\bar{\omega}_{m}, \theta_{n}\right) d \omega d \theta} \cos \left[\omega_{m n} t-k_{m n}\left(x \cos \theta_{n}+y \sin \theta_{n}\right)+\varepsilon_{m n}\right] \\
\omega_{m n}=\bar{\omega}_{m}-\frac{1}{2} d \omega+\left(n-1+R A N_{m n}\right) \frac{d \omega}{N_{\theta}}
\end{gathered}
$$

where $\varepsilon_{m n}$ means the random phase, uniformly distributed in the range $[0,2 \pi] ; R A N_{m n}$ is a random number that distribute evenly in the range of $[0,1]$, which is introduced to impart a random component to $\omega_{m n}$. The phase locking can be avoided by this method to simulate the multi-directional random wave.

With the combination of Eq.(16) and (26), the time series of multi-directional wave surface elevation $\eta(x, y, t)$ at any point in the domain with an array of large cylinders can be expressed as:

$$
\eta(x, y, t)=\sum_{m=1}^{M_{f}} \sum_{n=1}^{N_{\theta}} \sqrt{2 S\left(\bar{\omega}_{m}, \theta_{n}\right) d \omega d \theta}\left|T_{\eta}\left(x, y, \bar{\omega}_{m}, \theta_{n}\right)\right| \cos \left[\left(\omega_{m n} t-k_{m n}\left(x \cos \theta_{n}+y \sin \theta_{n}\right)+\varepsilon_{m n}\right]\right.
$$

Similarly, the wave force time series $f_{j}(t)$ on the cylinder can be written as follows considering Eq.(15) and (26)

$$
f_{j}(t)=\sum_{m=1}^{M_{f}} \sum_{n=1}^{N_{\theta}} \sqrt{2 S\left(\bar{\omega}_{m}, \theta_{n}\right) d \omega d \theta}\left|T_{f}^{j}\left(\bar{\omega}_{m}, \theta_{n}\right)\right| \cos \left[\left(\omega_{m n} t-k_{m n}\left(x \cos \theta_{n}+y \sin \theta_{n}\right)+\varepsilon_{m n}+\alpha_{m n}^{j}\right]\right.
$$

where $\alpha_{m n}^{j}=\arctan \frac{\operatorname{Re}\left(T_{f}^{j}\left(\bar{\omega}_{m}, \theta_{n}\right)\right)}{\operatorname{Im}\left(T_{f}^{j}\left(\bar{\omega}_{m}, \theta_{n}\right)\right)}$.

In the following simulation, $M_{f}=450$ and $N_{\theta}=350$ are used. The component waves are enough to represent the distribution of the wave energy with the frequency and direction. The calculated multidirectional waves can be spatially uniform and the 
waves are ergodic (Yu et al. 1991). That means though the simulated wave field clearly depends on the selected random phases, the statistical properties with the simulated waves should be independent of them. 


\section{Verification and calculated result analysis}

\subsection{Multi-directional wave parameters and the definition of the wave run-up and wave forces}

Table.1 shows the parameters of the multi-directional waves used in the calculation. In the table, $k_{p}$ denotes the wave number that corresponds to the peak wave period $T_{p}$. The values of the directional spreading parameter $s$ are chosen as 5 、 10、20、80 and 200.

Table.1. Parameters of the multi-directional waves

\begin{tabular}{|c|c|c|c|c|}
\hline$H_{1 / 3}(\mathrm{~m})$ & $T_{p}(\mathrm{~s})$ & $k_{p} a$ & $k_{p} d$ & $s$ \\
\hline 0.04 & 0.8 & 1.25 & 3.12 & 5、10、20、80、200 \\
\hline 0.04 & 0.9 & 1.01 & 2.52 & 5、10、20、80、200 \\
\hline 0.04 & 1.0 & 0.83 & 2.08 & 5、10、20、80、200 \\
\hline 0.04 & 1.1 & 0.71 & 1.77 & 5、10、20、80、200 \\
\hline
\end{tabular}

As shown in Eq.(21), the directional spreading parameter $s$ describes the degree of concentration of the directional distribution of the waves. Fig. 2 shows a comparison of directional distribution functions for different values of the directional spreading parameter $s$. The figure shows that as the parameter $s$ increases, the directional distribution becomes narrower. It can be seen that for large $s$, it does not represent the variation of the directional spreading width very well. To show the wave directionality quantitatively, the standard deviation $\sigma_{\theta}$ of the directional distribution will be also used in the following analysis. This standard deviation of a directional spreading is defined as

$$
\sigma_{\theta}=\left\{\int_{-\frac{\pi}{2}}^{\frac{\pi}{2}} G(f, \theta)\left[\begin{array}{lll}
\theta & \phi_{0}^{2} & d
\end{array}\right\}^{\frac{1}{2}} \theta .\right.
$$

The relationship between the directional spreading parameter $s$ and the standard deviation $\sigma_{\theta}$ is shown in Fig. 3. It shows that the standard deviation changes rapidly for small value of $s$. But when $s$ is large, for example, $s>80$, the standard deviation changes slowly. If the spreading parameter is large enough, the multi-directional wave can be assumed to be unidirectional. 


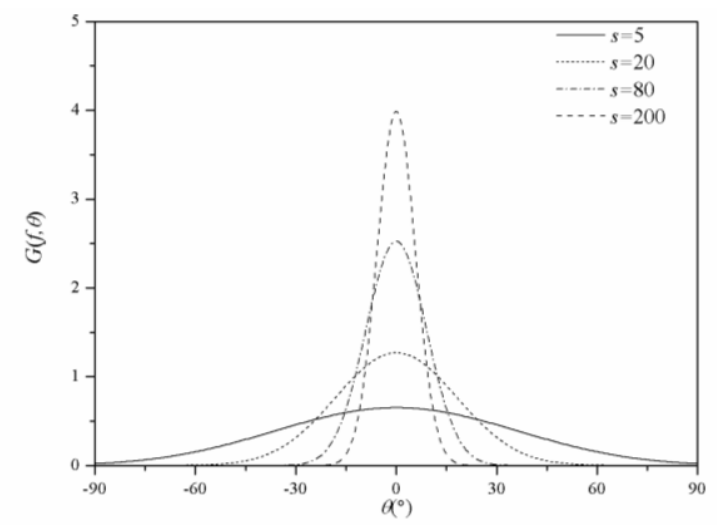

Fig. 2 The value of directional distribution functions for different directional spreading parameter $s$

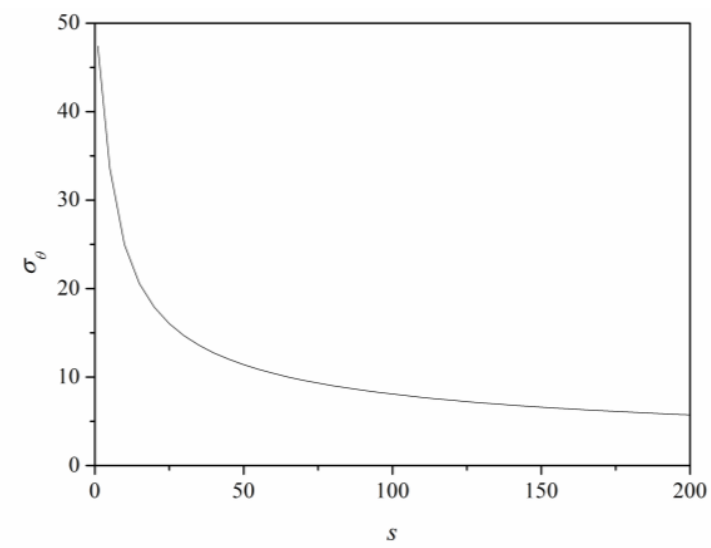

Fig. 3 The relationship of directional spreading parameter $s$ with the standard deviation $\sigma_{\theta}$

From Eq. (28) and Eq. (29), the time series of wave surface elevation and wave force on cylinders can be calculated with given incident wave parameters. In the present simulation, 16384 data points are collected at a sampling rate of $50 \mathrm{~Hz}$ in each case. The sampling data are statistically analyzed to obtain the significant wave height and the wave forces on the cylinder array. For these calculations, the cylinders are of equal diameter $0.4 \mathrm{~m}$ and the water depth is kept constant at $0.5 \mathrm{~m}$.

The wave run-up and wave force are important factors in the design of the marine structures. To show the phenomenon of multi-directional waves acting on large scale vertical cylinder arrays more clearly, the following dimensionless form will be used to describe the wave run-up. i.e.,

$$
R=\frac{A-A_{0}}{A_{0}}
$$

where $A_{0}$ is the significant amplitude of the incident wave, and $A$ is the calculated significant amplitude at different locations around the cylinders. Similarly, the non-dimensional normal force $F_{x}$ and transverse force $F_{y}$ are defined in a 


\section{dimensionless form as}

$$
F_{x}=\frac{f_{x}}{\rho g H_{0} a^{2}} ; \quad F_{y}=\frac{f_{y}}{\rho g H_{0} a^{2}}
$$

where $f_{x}$ and $f_{y}$ are the significant normal and transverse wave forces, respectively, on the cylinders and $H_{0}$ is the significant wave height of the incident waves.

It should be noted that, the purpose of this paper is to investigate the effect of wave directional spreading on multi-directional wave loads on an array of cylinders. Because the significant values are more stable and reliable, they are used to investigate the effect of the wave directionality on the multi-directional wave run-up and force on the cylinders. In fact, because we use the linear transfer function to calculate the multi-directional wave loads, the wave force and run-up are the linear output results for the incident waves and therefore the characteristic value of the maximum and the significant value for wave loads are similar with the incident wave pattern.

\subsection{Model verification}

To investigate the validity of the numerical model, the calculated results are compared with the experimental data about the multi-directional wave interaction with a square array of cylinders. The laboratory experiment was carried out in a wave basin at the State Key Laboratory of Coastal and Offshore Engineering (SLCOE), Dalian University of Technology, China. The basin is $55.0 \mathrm{~m}$ long, $34.0 \mathrm{~m}$ wide and $0.7 \mathrm{~m}$ deep. A multi-directional wave-maker system was installed on one side of the basin. The wave-maker system included 70 segments, each $1.0 \mathrm{~m}$ high and $0.40 \mathrm{~m}$ wide, resulting in a system with a total length of $28.0 \mathrm{~m}$. To adapt the infinite extent of the fluid for the wave-structures interaction, wave absorbers were arranged along the other three sides of the basin to absorb incoming waves and prevent the wave reflections from the boundary of the wave basin.

Fig. 4 shows the layout of the square array with four cylinders with the same diameter $D=0.4 \mathrm{~m}$. In the experiment, the principal wave direction $\theta_{0}=0^{\circ}$, therefore the layout is symmetrical along the main wave direction. So the wave loads on cylinder 1 and cylinder 4 are used on behalf of the front and back cylinders, respectively. Eight wave gauges were arranged around the cylinder 1 and cylinder 4 to measure the wave run-up on the cylinder. The angles $\alpha$, which represents the point for the calculation of the wave run up on the cylinder, in the front and back cylinder are $0^{\circ}, 45^{\circ}, 90^{\circ}, 135^{\circ}$, $180^{\circ}, 225^{\circ}, 270^{\circ}$ and $315^{\circ}$. The water depth was kept constant at $0.5 \mathrm{~m}$ in the experiment. Fig.5 displays the sketch of experiment for the multi-directional random wave loads on the square array of large-scale cylinders in the wave basin. 


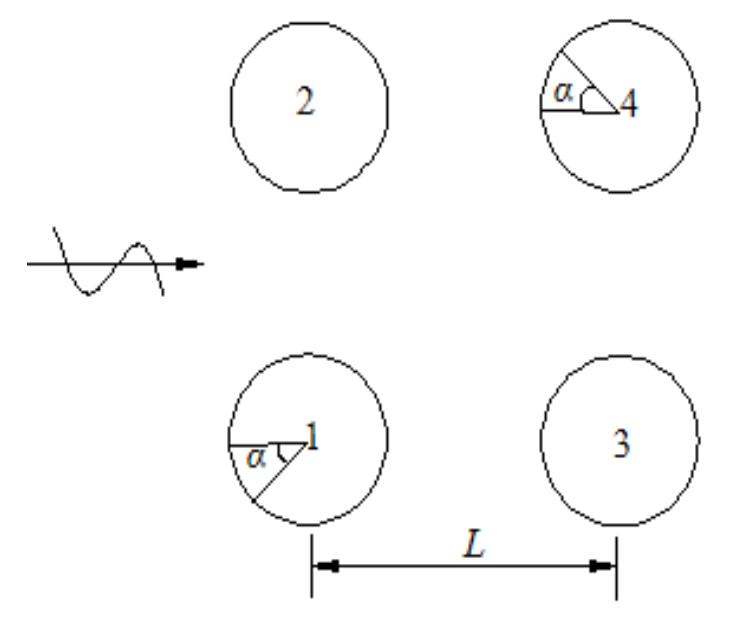

Fig.4 Layout for the square array with four cylinders

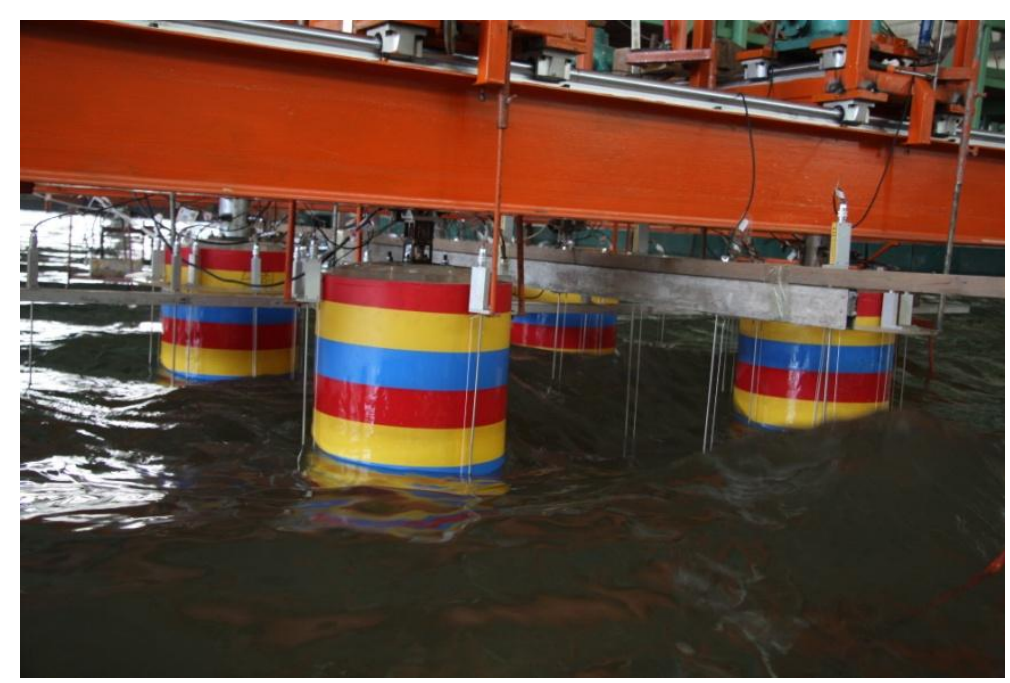

Fig.5 Sketch of the experiment for multi-directional irregular wave loads on large-scale cylinders in the wave basin

Fig.6 and Fig.7 present the comparison of the numerically calculated wave run-up and wave force with the experimental results for multi-directional wave $\left(T_{p}=0.9 \mathrm{~s}\right.$, $\left.k_{p} a=1.01, H_{1 / 3}=0.04 \mathrm{~m} ; L=1.5 \mathrm{D}\right)$ interaction with the array of cylinders with different directional spreading $s$. It can be seen that good agreement for the wave loads on the cylinders was found in spite of the fact that the experimental values are a little bigger than the calculated results. The difference between the calculated results and the experimental results may be caused by two facts. The first is that the calculation theory is based on linear theory, but the experimental waves include nonlinear effects in some extent. Secondly, the irregular waves include different frequency waves. For the lower frequency wave components, the dimension of the cylinder may belong to small scale cylinder, the diffraction theory may cause some errors.

The compared results are identical to that given by Kriebel $(1992,1998)$, who 
investigated the wave run-up and wave force carried out in 22 laboratory experiments. He found that both the measured and the predicted maximum forces exceeded the predictions of the linear theory by $5-15 \%$, and the measured maximum wave run-up exceeded the predictions of the linear theory by $44 \%$.
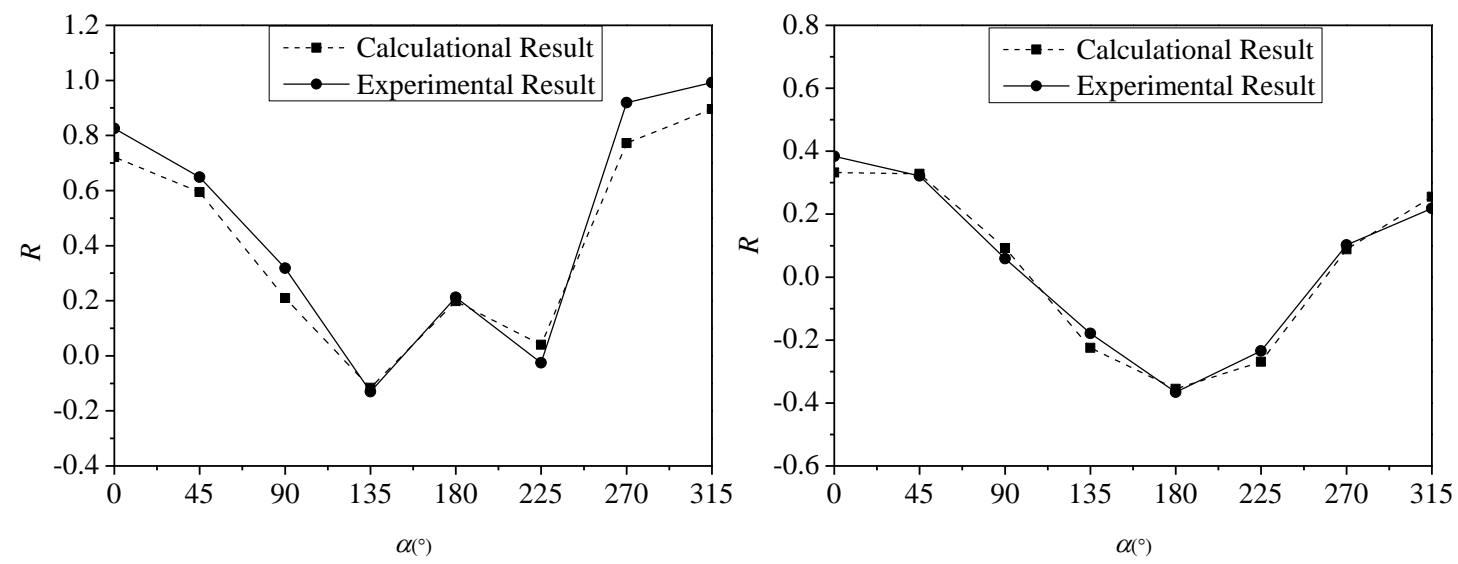

(a) $s=10$
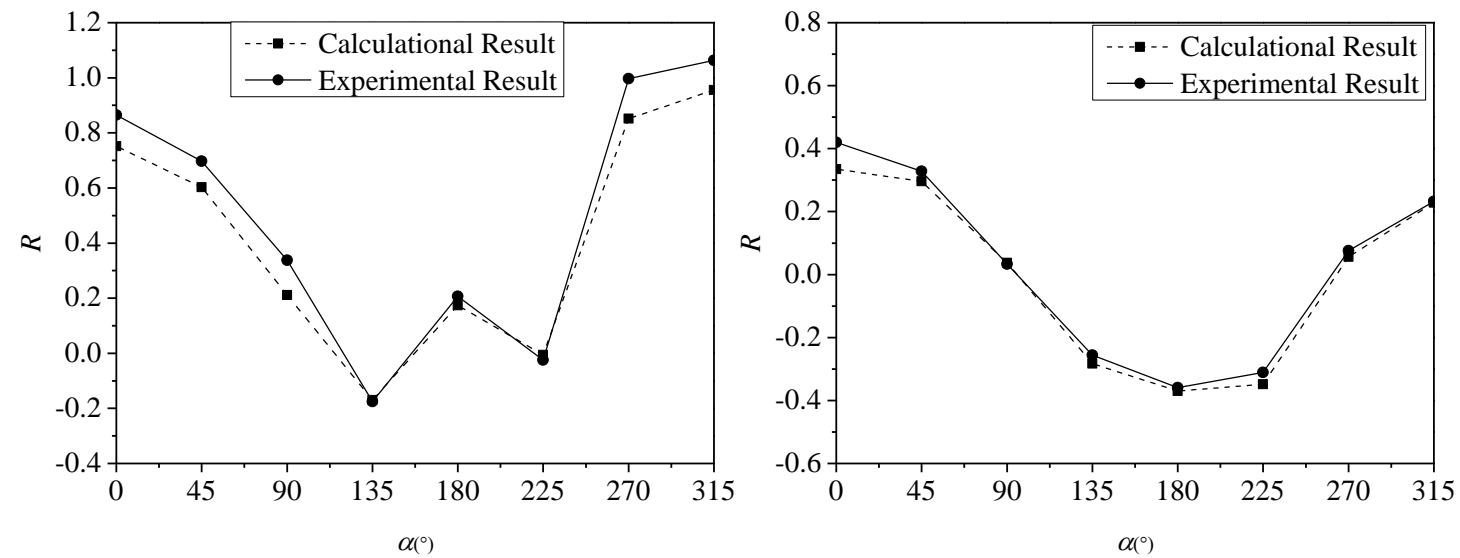

(b) $s=20$
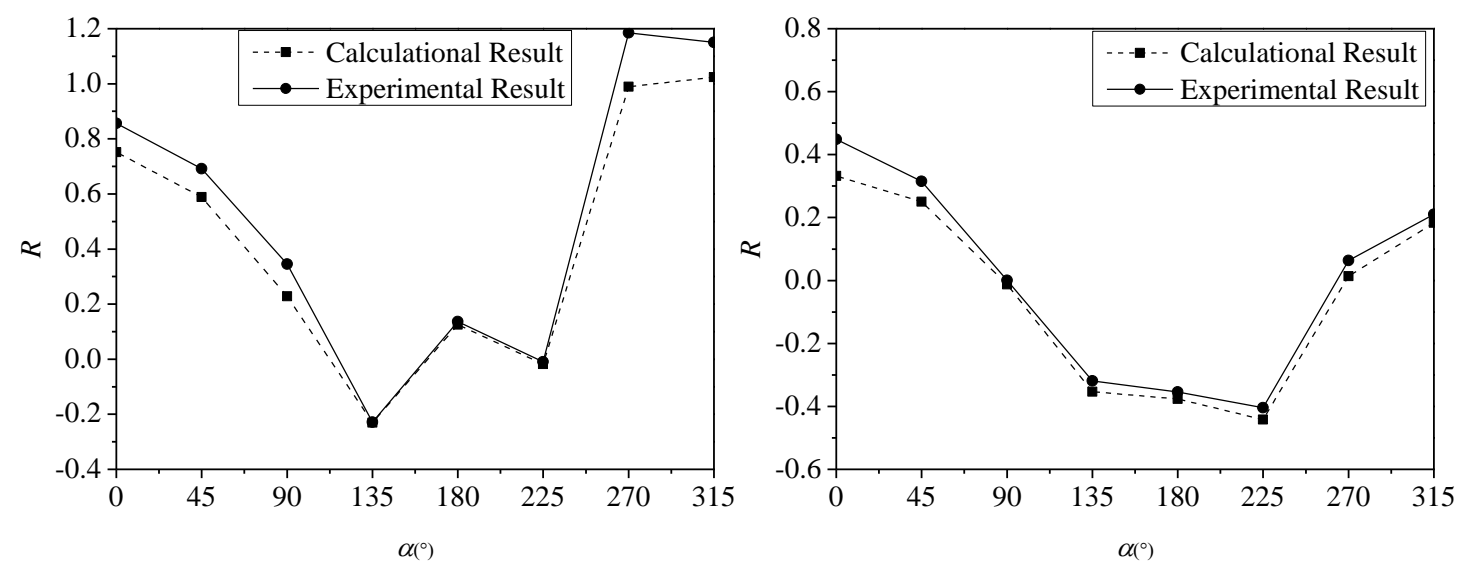

(c) $s=80$

Fig. 6 The comparison of the numerically calculated wave run-up with experimental results for different directional spreading parameters $s\left(L=1.5 D, T_{p}=0.9 \mathrm{~s}, k_{p} a=1.01\right.$, 
$H_{1 / 3}=0.04 \mathrm{~m}$; the left part for the front cylinders and the right ones for the back cylinders)
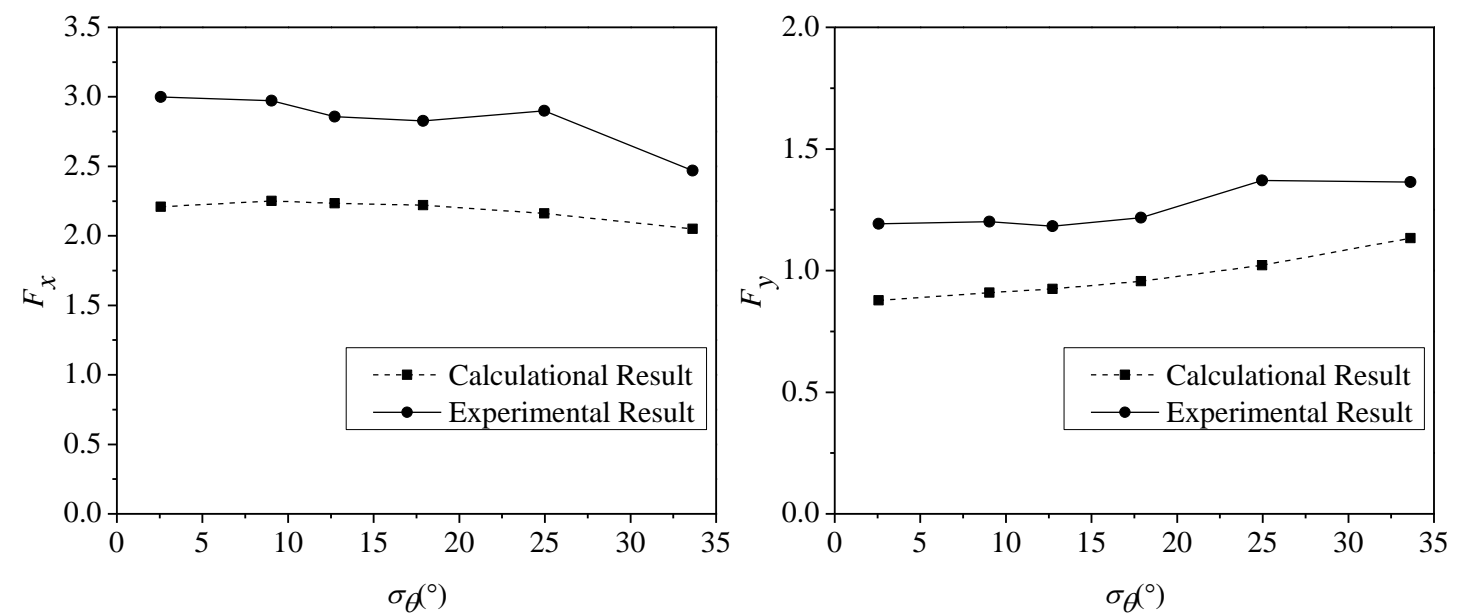

(a) The variation of the wave force on the front cylinders with the variance of the wave directional spreading
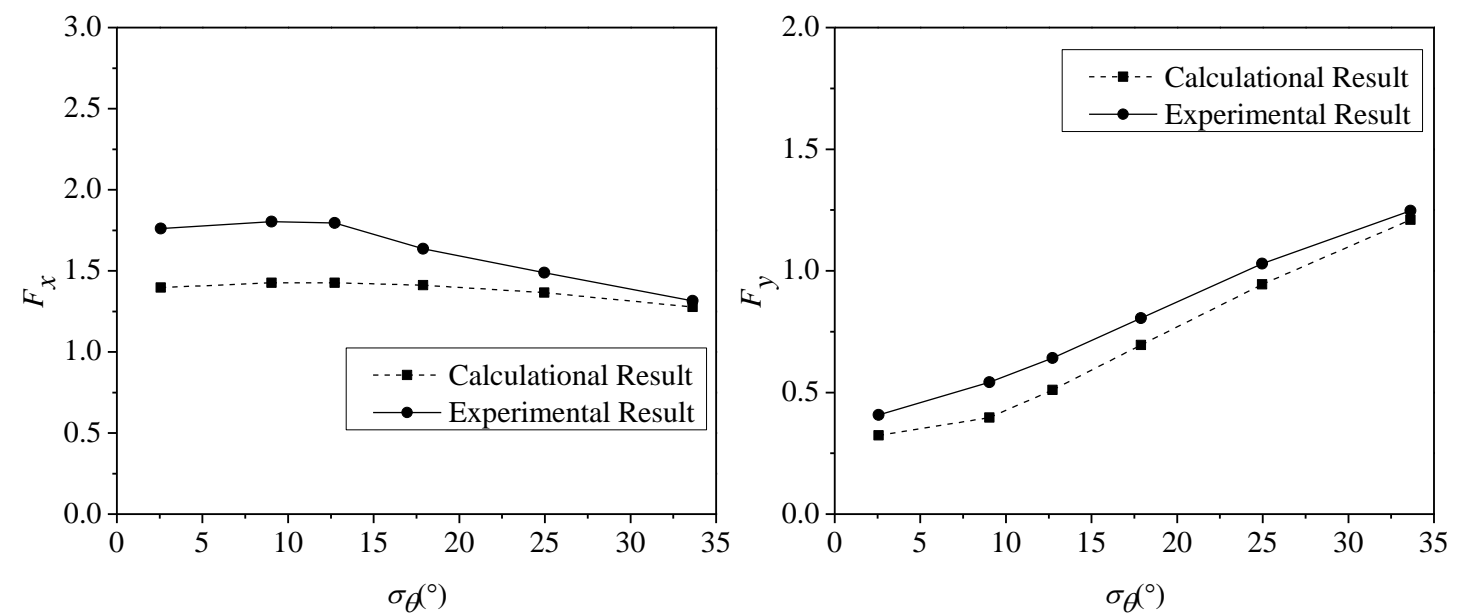

(b) The variation of the wave force on the back cylinders with the variance of the wave directional spreading

Fig. 7 The comparison of the numerically calculated wave force with experimental results for different wave directionality $\left(L=1.5 D, T_{p}=0.9 \mathrm{~s}, k_{p} a=1.01, H_{1 / 3}=0.04 \mathrm{~m}\right.$; the left part for the normal force, the right part is the transverse force)

\subsection{Analysis of the calculated multi-directional wave run-up}

Damage to the lowest deck of multi-column platforms has been reported, as for example discussed in Swan et al. (1997), and such cases could be due to underestimation of the prevailing wave condition and the unreliable prediction of the wave elevation and upwelling during the design of the platforms. To investigate the effect of wave directionality on multi-directional wave run-up and wave forces on an array of cylinders, the attention is focused on the wave loads on two cylinders and four cylinders. 


\subsubsection{Multi-directional random wave interaction with $\mathbf{2}$ cylinders}

The layouts of the two cylinders are presented in Fig. 8 for the cylinders in parallel and in tandem, respectively. The gap $L$ between the two cylinders varies from $1.5 D$ up to $5.0 D$.

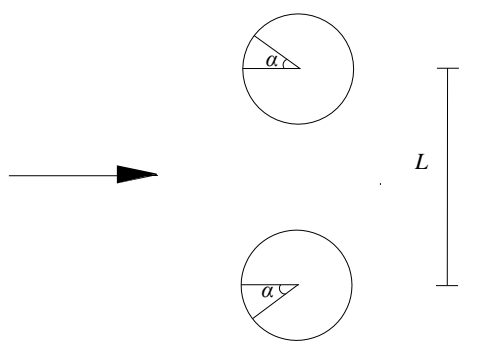

(a) Parallel layout

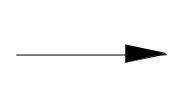

Fig.8 Different layouts of two cylinders

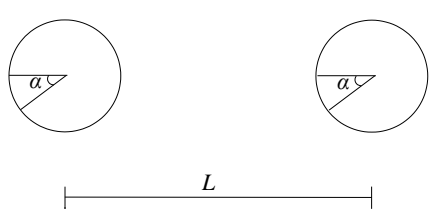

(b) Tandem layout

Fig.9 shows the multi-directional wave run-up on two cylinders in the parallel arrangement. Since the two cylinders are symmetrical along the principal wave direction, as expected, the wave run-up on the symmetrical points has similar results. It should be noted that in some points the values have a little difference. The reason is that the incident wave is a multi-directional random wave. There are therefore some asymmetries to the waves in space during the calculation because the time series are calculated with the summation model. The errors may be dependent on the extent of the uniformity of the random phases $\varepsilon_{m n}$ in Eq.(28). Anyway, for this symmetrical layout, only one cylinder's result is chosen to investigate the effect of multi-directional random wave on wave run-up.

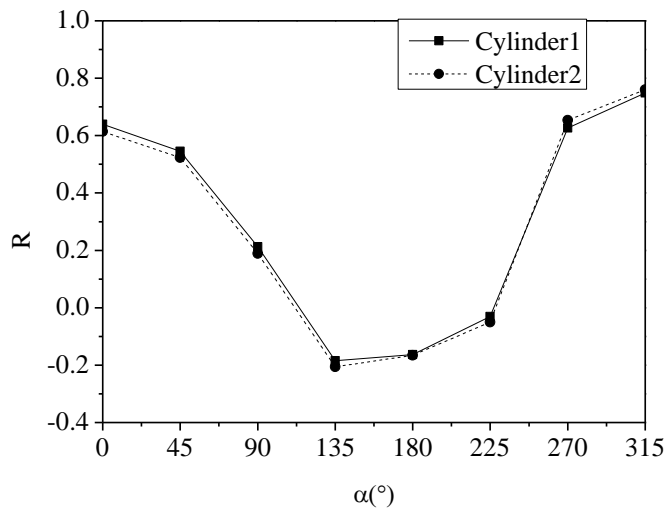

(a) $L=1.5 D, T_{p}=0.9 \mathrm{~s}, s=10$

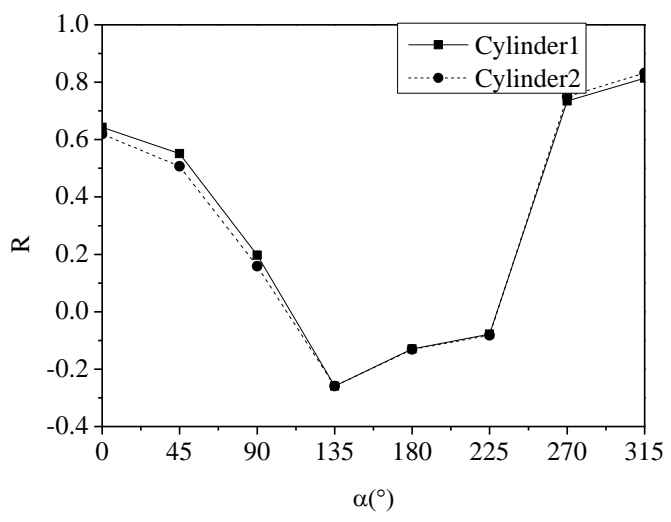

(b) $L=1.5 D, T_{p}=0.9 \mathrm{~s}, s=40$ 


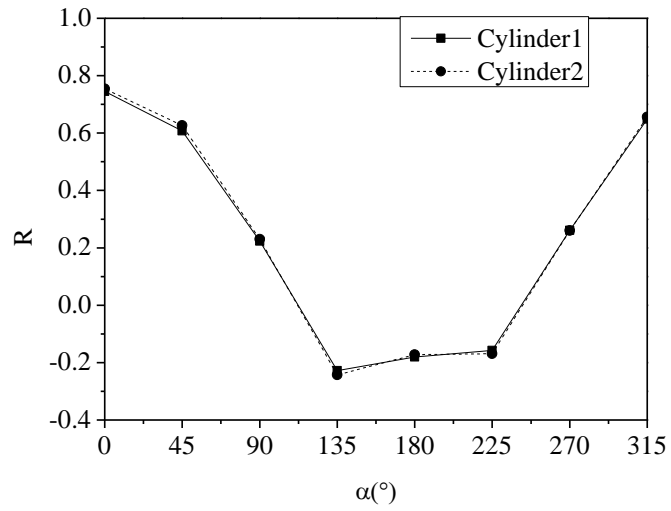

(c) $L=3.0 D, T_{p}=0.9 \mathrm{~s}, s=20$

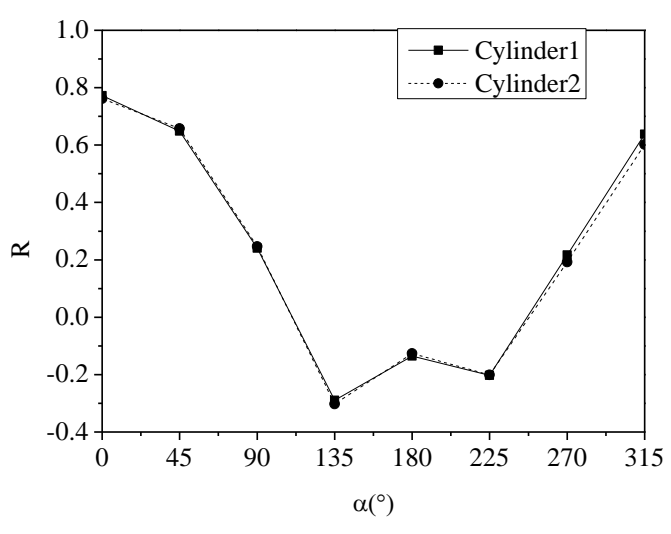

(d) $L=3.0 D, T_{p}=0.9 \mathrm{~s}, s=80$

Fig.9 Wave run-up on two cylinders in parallel

As our attention is focused on real sea wave interaction with cylinders, we mainly discuss the effect of wave directionality on the wave run-up and forces. Fig.10 (a) (d) shows the multi-directional wave run-up on two parallel cylinders with different $\operatorname{spacing}(L=1.5 D 、 2.0 D 、 3.0 D$ and $5.0 D)$ for various directional spreading parameters $s$. It can be found that the effect of the wave directionality on the wave run-up depends on the position on the cylinder. In the front parts of the cylinders and at $\alpha=180^{\circ}$, the wave run-up increases as the directional spreading parameter $s$ becomes lager. On the other hand, at the back parts, as the directional distribution becomes wider, the wave run-up increases. In the range $\alpha=\left[0^{\circ}, 180^{\circ}\right]$, the wave run-up parameter $R$ decreases as $\alpha$ increases. However, the minimum value of the wave run-up is dependent on the directional spreading parameter. When the directional spreading parameter $s$ is small, this minimum value occurs at $180^{\circ}$ or $135^{\circ}$. The result is quite similar with the multi-directional run-up on a single cylinder that was shown by Ji et al. (2015).
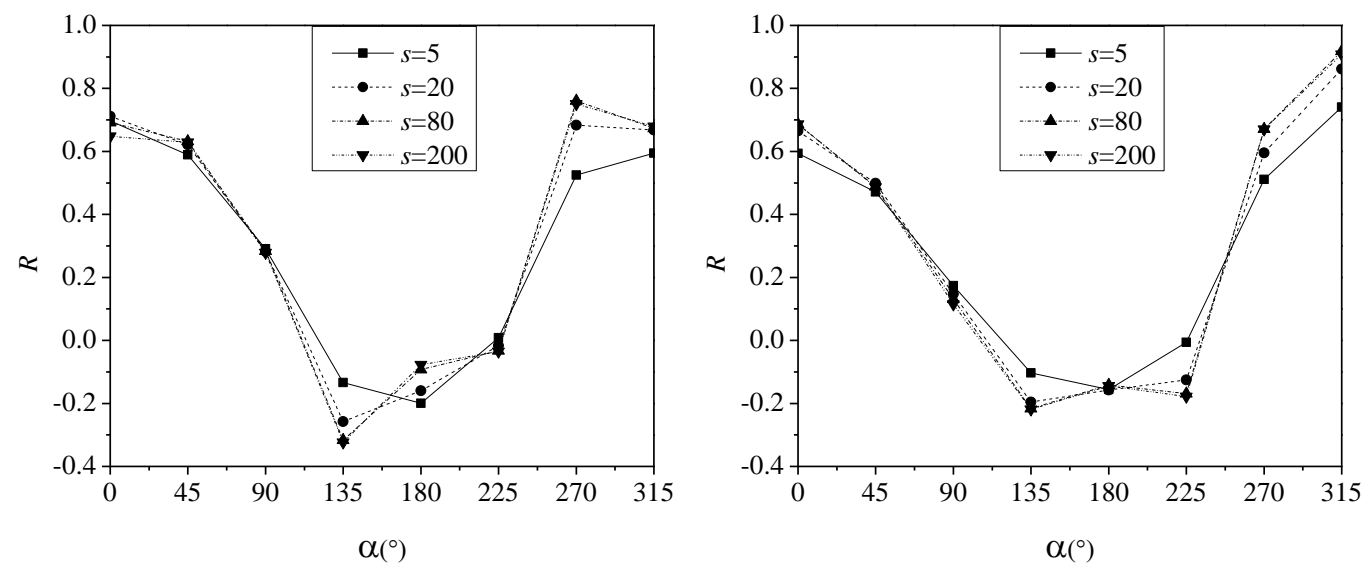

(a) $L=1.5 D$ 

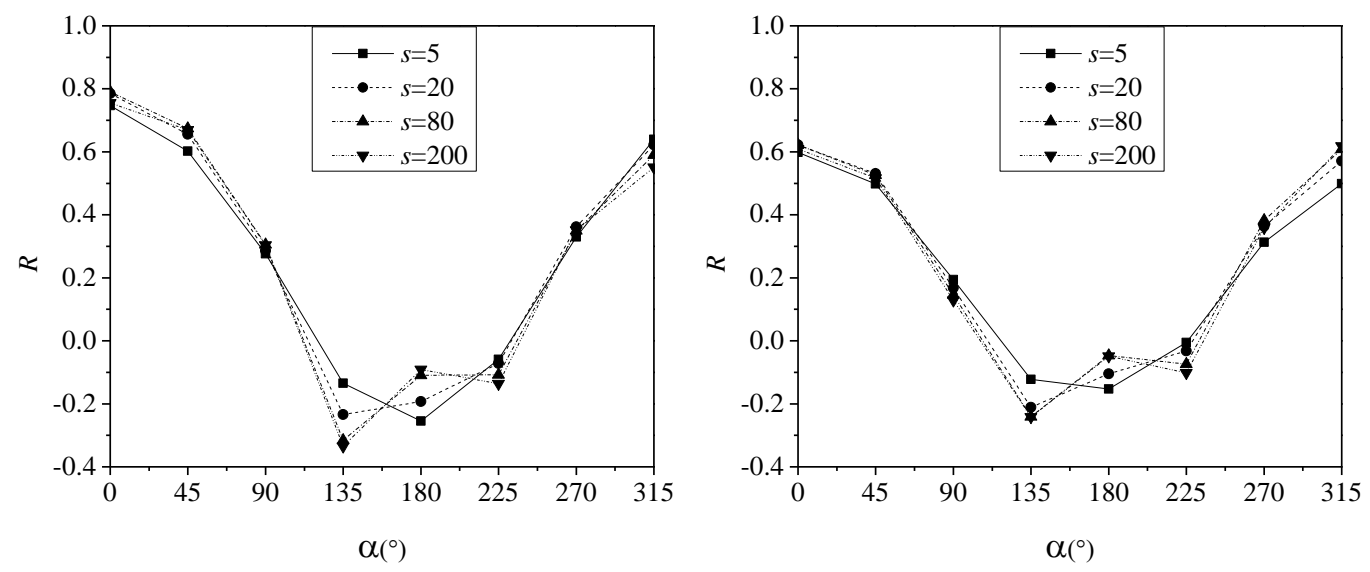

(b) $L=2.0 \mathrm{D}$
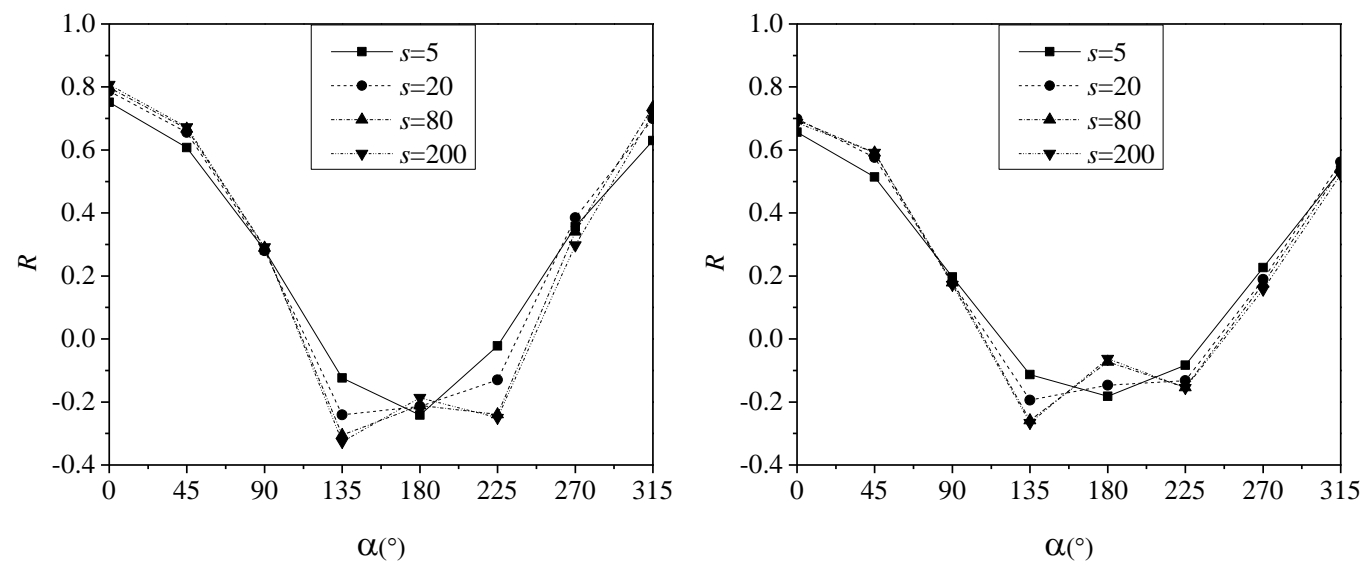

(c) $L=3.0 D$
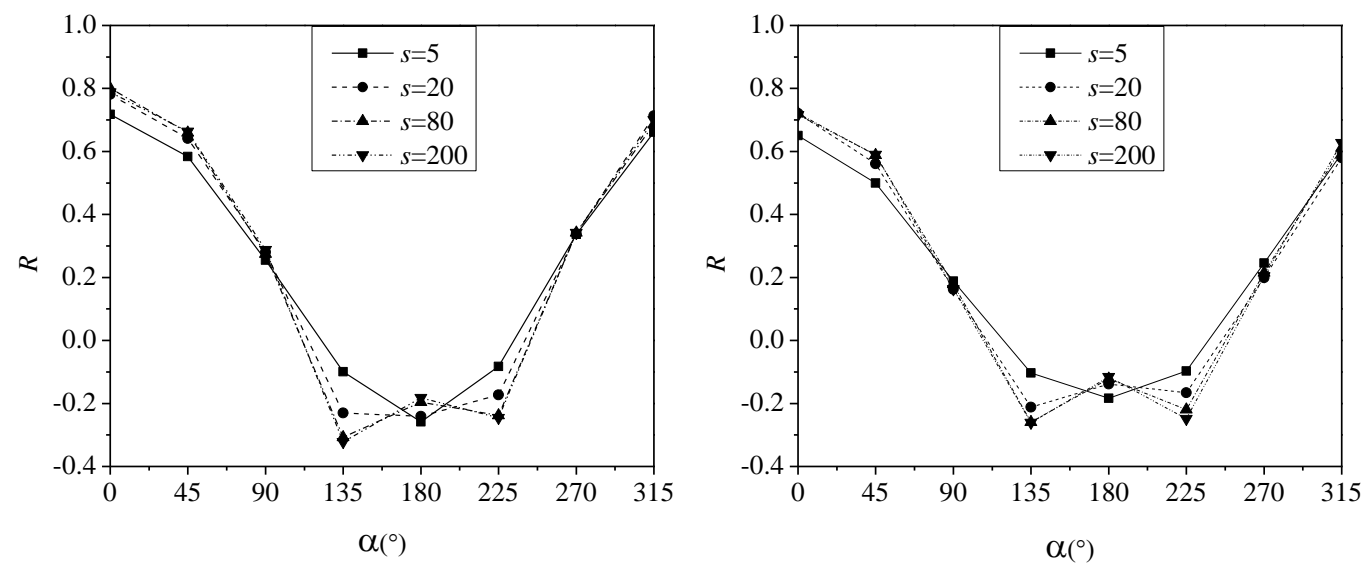

(d) $L=5.0 \mathrm{D}$

Fig.10 The multi-directional wave run-up on cylinders in a parallel layout with different spacing (the left ones for $T_{p}=0.8 \mathrm{~s}, k a=1.26$, the right ones for $T_{p}=1.0 \mathrm{~s}, k a=$

In Fig.11, the multi-directional random wave run-up on the cylinders in tandem is presented. For this kind of layout, as expected, the values of the wave run-up on a cylinder at symmetrical positions are basically identical to each other. It can be found 
that the front cylinder has the cover effect to the back one. As the gap $L$ increases, the cover effect becomes weakened. The effects of wave directionality on the two cylinders are different. For the front cylinder, at the front parts, the wave run-up increases as $s$ becomes larger, while it is opposite at the back part. But for the back cylinder, the wave run-up increases as the directional spreading parameter $s$ decreases, i.e., the directional spreading become wider. As discussed above, in the case of $s=200$, the directional spreading is very narrow and the waves tend to be unidirectional waves. This means that the wave run-up for a multi-directional wave condition is larger than that for unidirectional waves. The reason may be because the diffracted and scattered waves for multi-directional waves from the array of cylinders, that may increase the wave run-up on the cylinders. In the process of designing marine structures, the standards based on unidirectional waves may not give a conservative estimate.
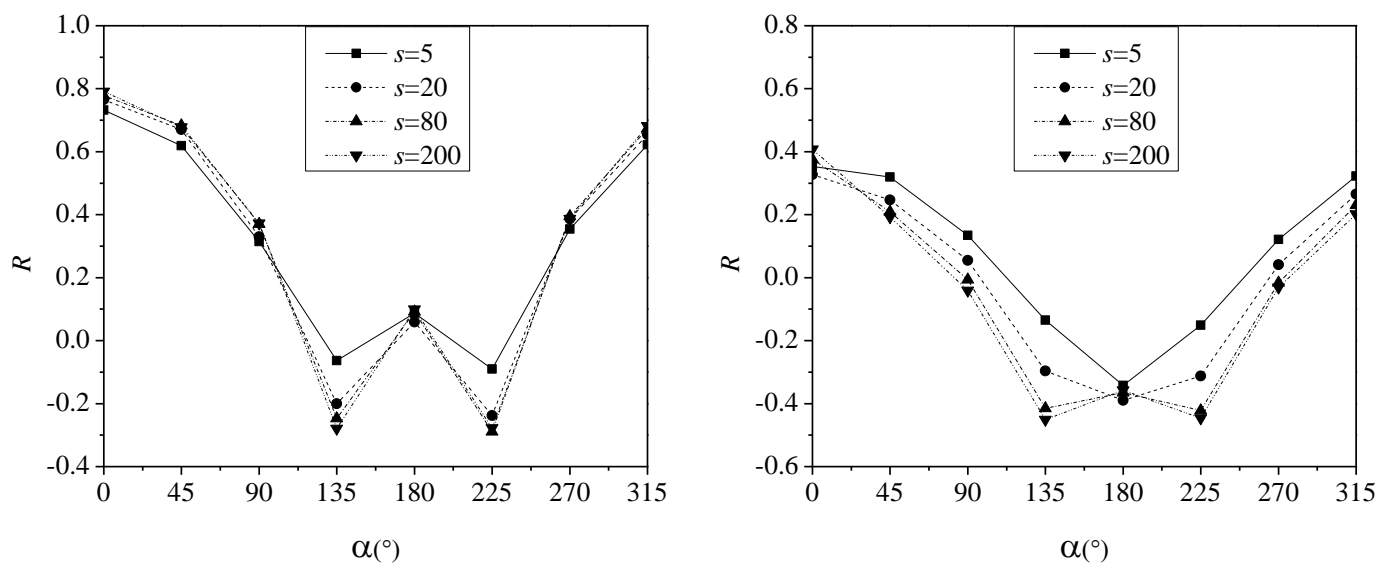

(a) $L=1.5 \mathrm{D}$
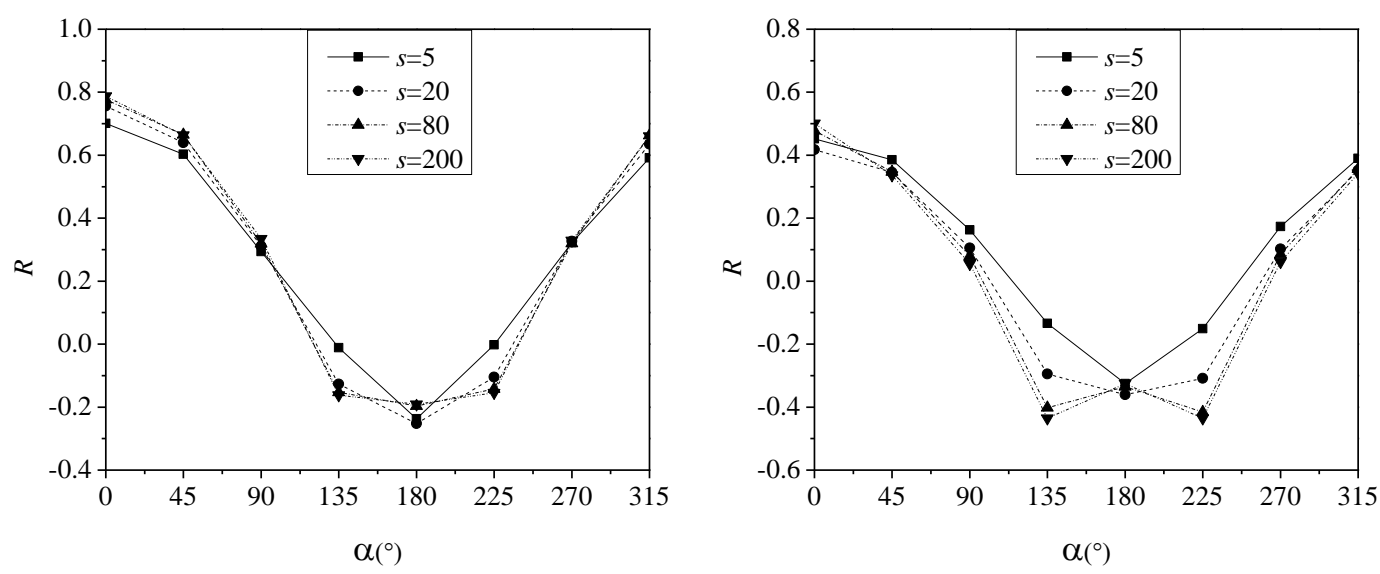

(b) $L=2.0 D$ 

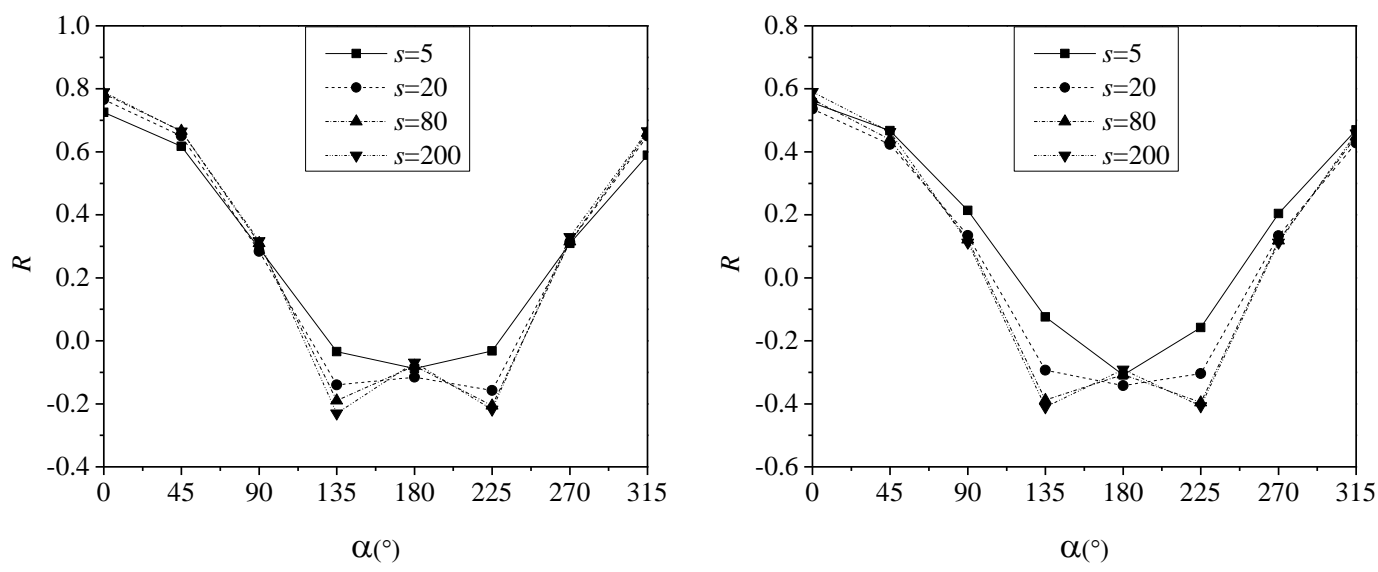

(c) $L=3.0 \mathrm{D}$
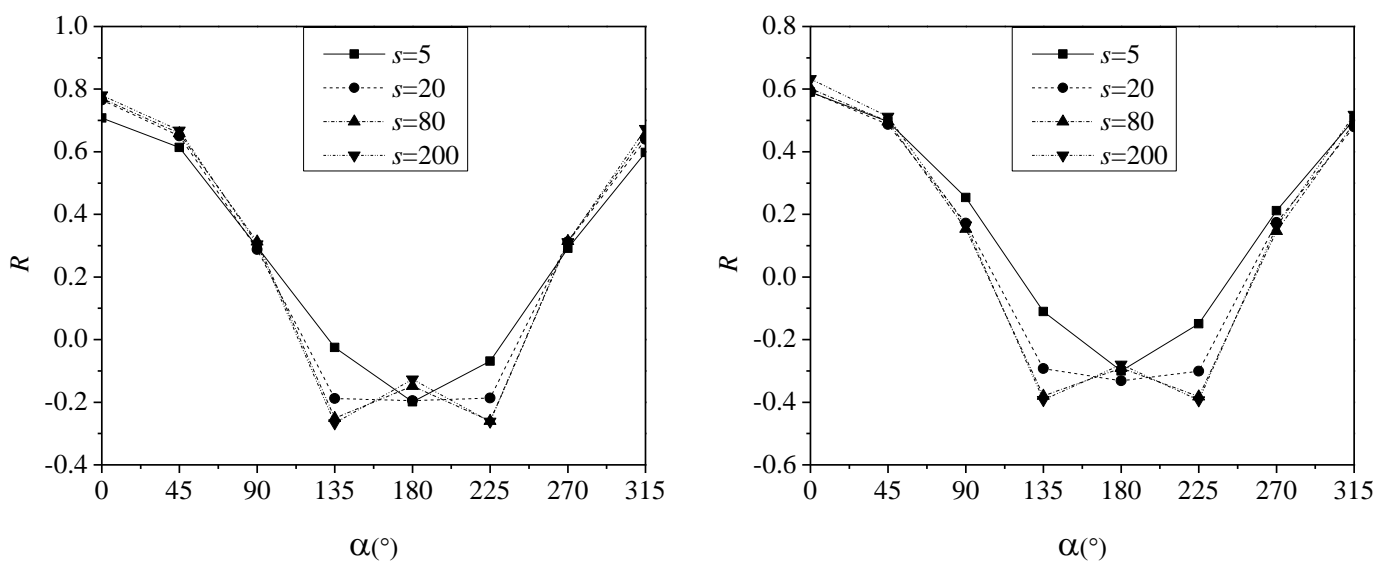

(d) $L=5.0 \mathrm{D}$

Fig. 11 Multi-directional wave run-up on cylinders for the tandem layout with different spacing $\left(T_{p}=0.8 \mathrm{~s}, k_{p} a=1.26\right.$; the left ones for the front cylinder, the right ones for the back cylinder)

An array of cylinders is often used in practical engineering, as for example in the case of a Tension Leg Platform or the foundation for a floating offshore airport. In the present paper, the typical cylinder array with four cylinders is used to investigate the effect of wave directionality on the wave run-up. The sketch of the layout for a square array can be found in Fig.5. The diameter $D$ for the cylinders is $0.4 \mathrm{~m}$. The angles $\alpha$ in the front and back cylinder are $0^{\circ}, 45^{\circ}, 90^{\circ}, 135^{\circ}, 180^{\circ}, 225^{\circ}, 270^{\circ}$ and $315^{\circ}$. Since the layout is symmetrical along the main wave direction, the wave run-un on cylinder 1 and cylinder 4 are used on behalf of the front and back cylinders, respectively.

As an example, Fig.12 gives the perspective view of the wave surface near the cylinders at the time of $t=100 \mathrm{~s}$ for multi-directional random waves $\left(H_{1 / 3}=0.04 \mathrm{~m}\right.$, $T_{p}=0.8 \mathrm{~s}$ and $L=2 D$ ) with different directional spreading parameter $s$. It is obvious that different from the unidirectional wave situation, the wave directionality should have special effect on wave loads due to the short-crested properties. As the directional 
spreading parameter increases, the wave energy distributes concentrated in direction domain and the wave crest line becomes longer. Wave surface for the case $s=200$ is very close to unidirectional.

Fig.13 15 shows the multi-directional wave run-up around the square array of cylinders with different spacing $(L=1.5 D 、 2.0 D 、 3.0 D)$. It clearly shows that at most of the points, similar to the results for two cylinders in tandem, for the small spacing (Fig.13), at the front part of the front cylinders, the wave run-up increases as $s$ becomes larger, while it is opposite at back part. But for the back cylinders, the wave run-up increases as the directional spreading parameter $s$ decreases. As the spacing $L$ increases, the cover effect of the front cylinder for the back cylinder decrease and the multi-directional wave run-up on the front and back cylinders are similar to that on a single cylinder that shows in Ji et al. (2015).
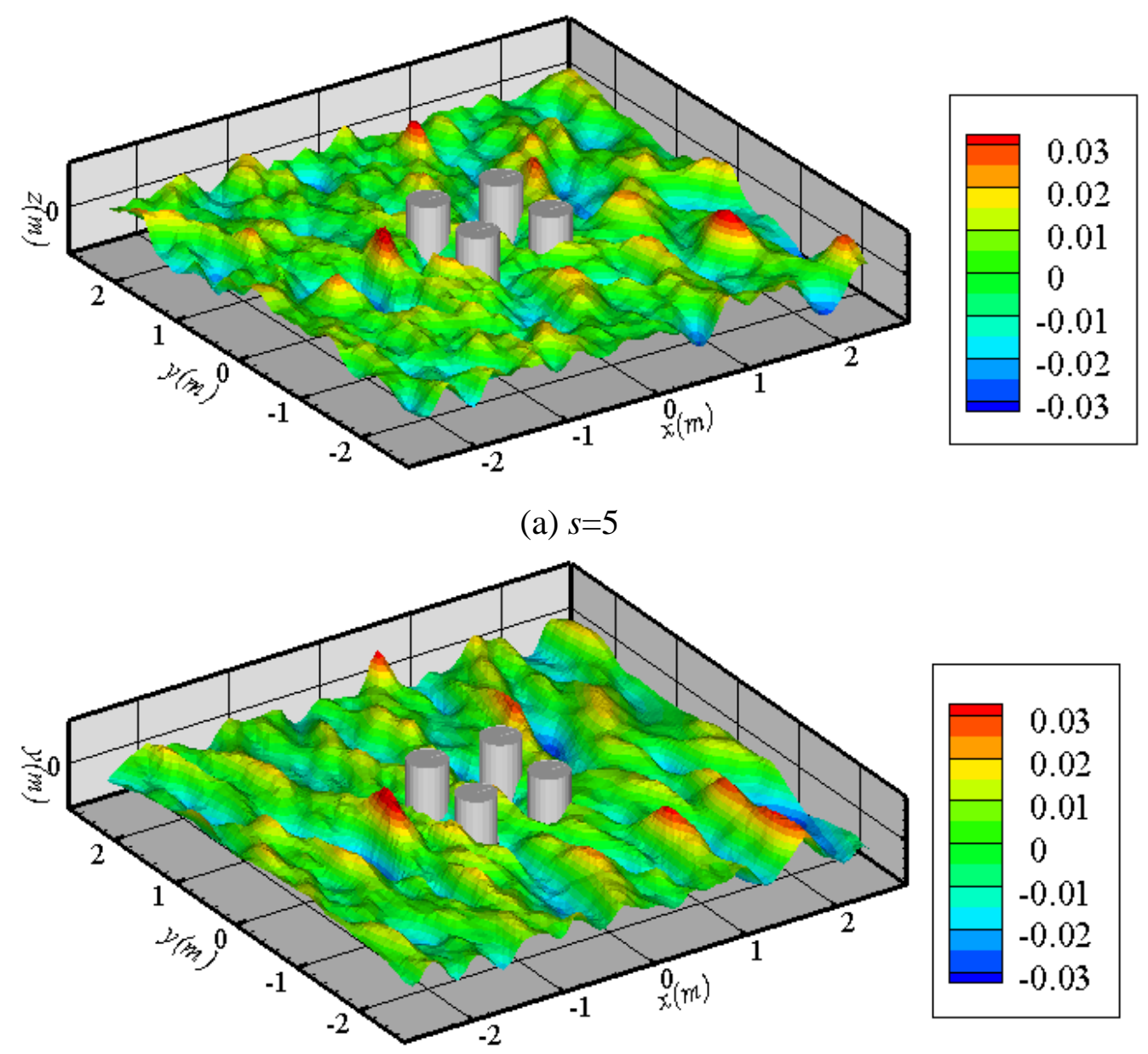

(b) $s=20$ 

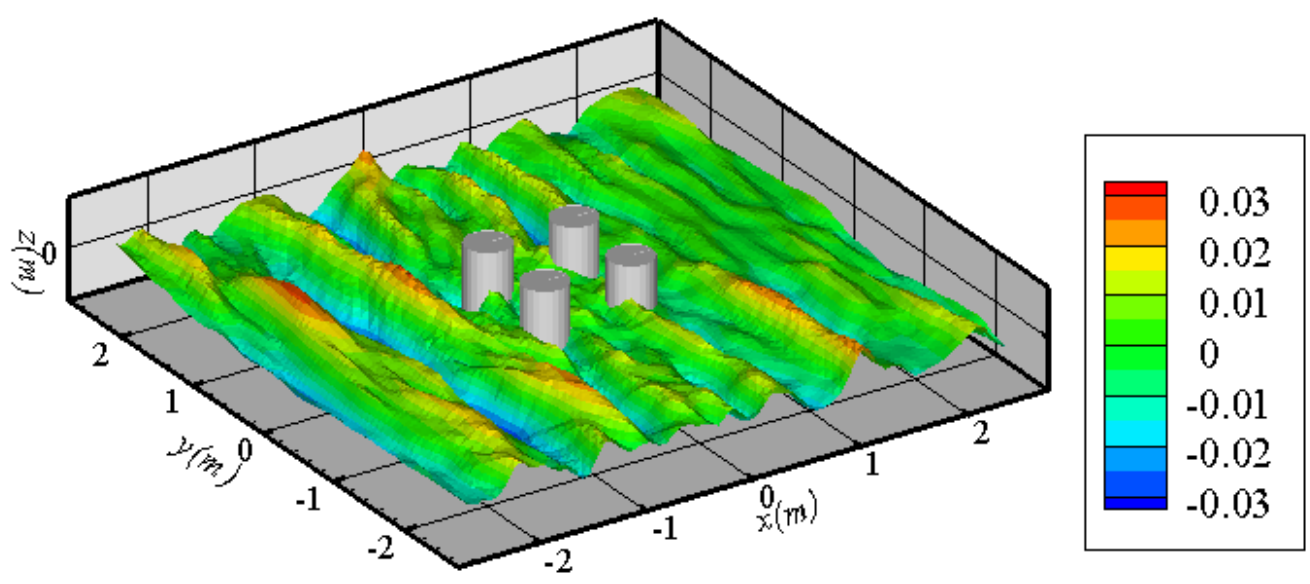

(c) $s=80$
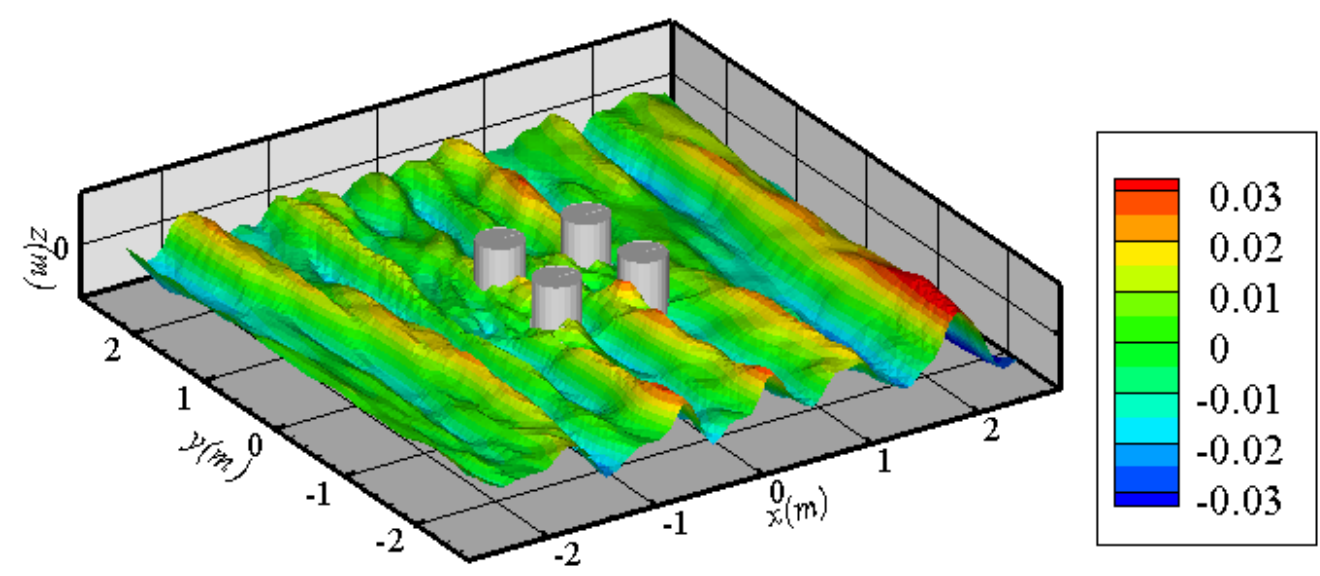

(d) $s=200$

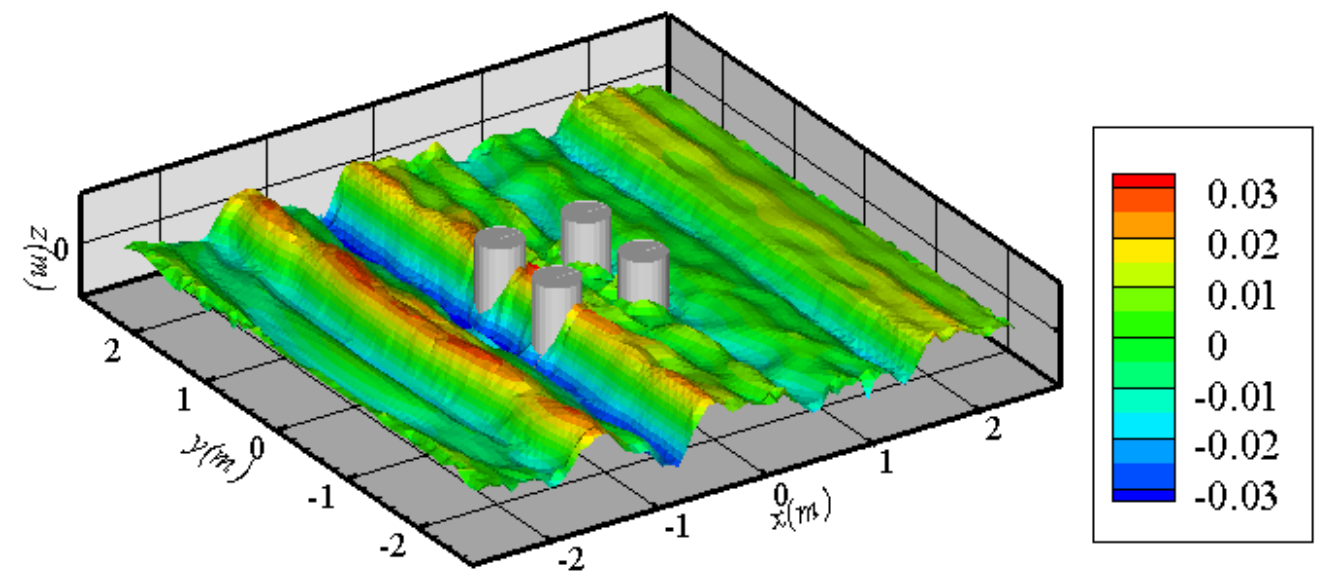

(e) $s=\infty$

Fig.12 Perspective view of the wave surface elevation at $t=100 \mathrm{~s}$ for different directional spreading parameter $s\left(H_{1 / 3}=0.04 \mathrm{~m}, T_{p}=0.8 \mathrm{~s}, k_{p} a=1.26 ; L=2.0 D\right)$ 

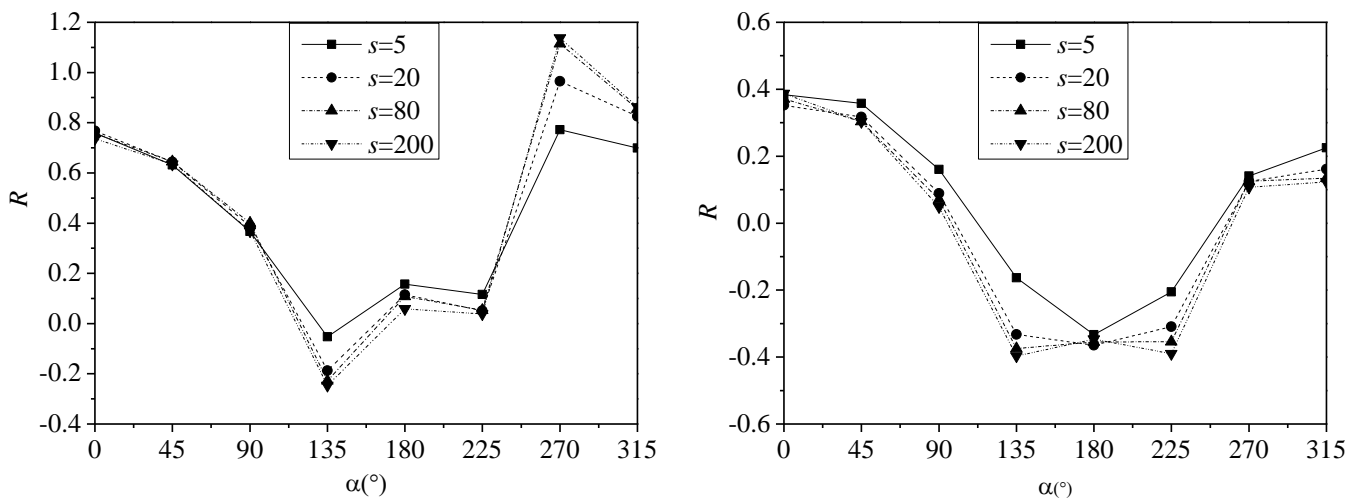

(a) $L=1.5 D, T_{p}=0.8 \mathrm{~s}, k_{p} a=1.26$
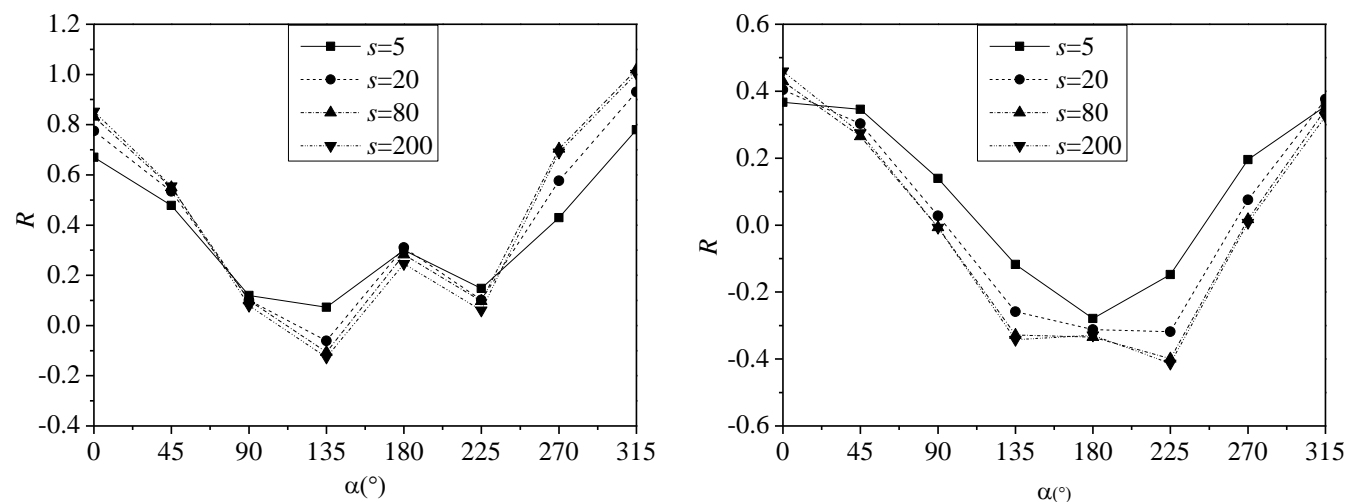

(b) $L=1.5 D, T_{p}=1.0 \mathrm{~s}, k_{p} a=0.83$

Fig. 13 The multi-directional wave run-up on four cylinders with $L=1.5 D$ for different directional distribution spreading parameter $s$ (The left part for the front cylinder, the right for the back cylinder)
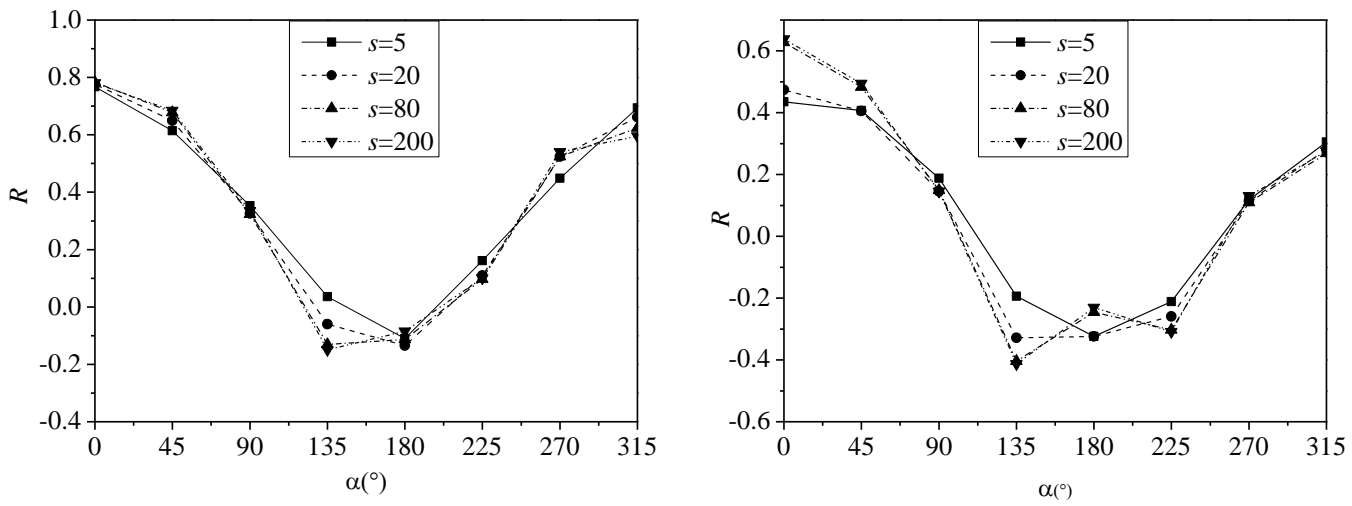

(a) $L=2.0 D, T_{p}=0.8 \mathrm{~s}, k_{p} a=1.26$ 

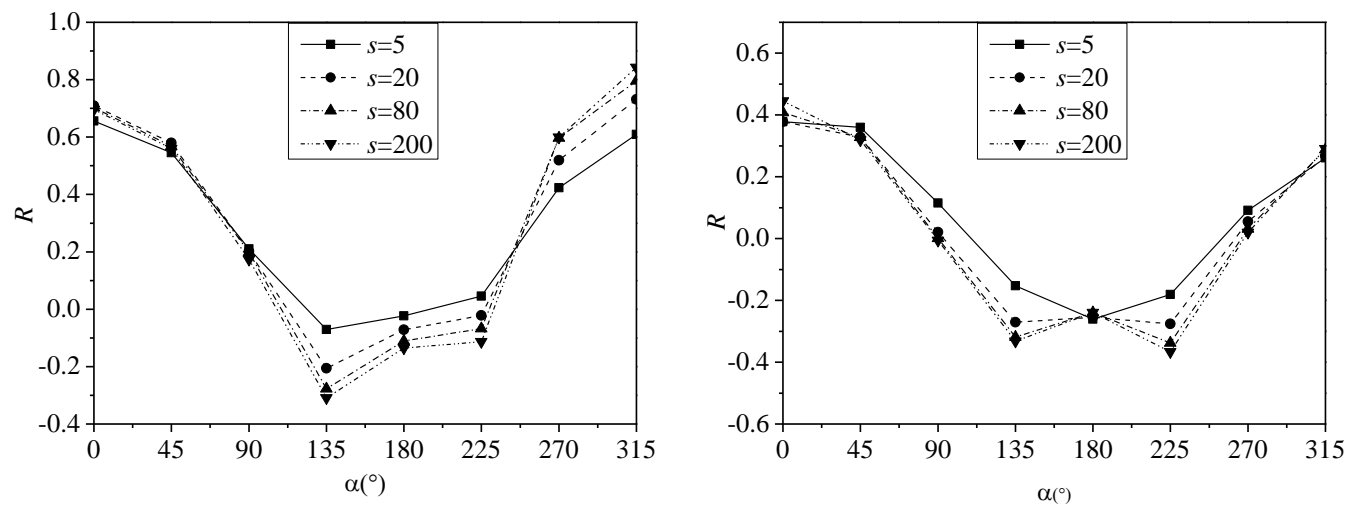

(b) $L=2.0 D, T_{p}=1.0 \mathrm{~s}, k_{p} a=0.83$

Fig. 14 The multi-directional wave run-up on four cylinders with $L=2.0 \mathrm{D}$ for different directional distribution spreading parameter $s$ (The left part for the front cylinder, the right for the back cylinder)
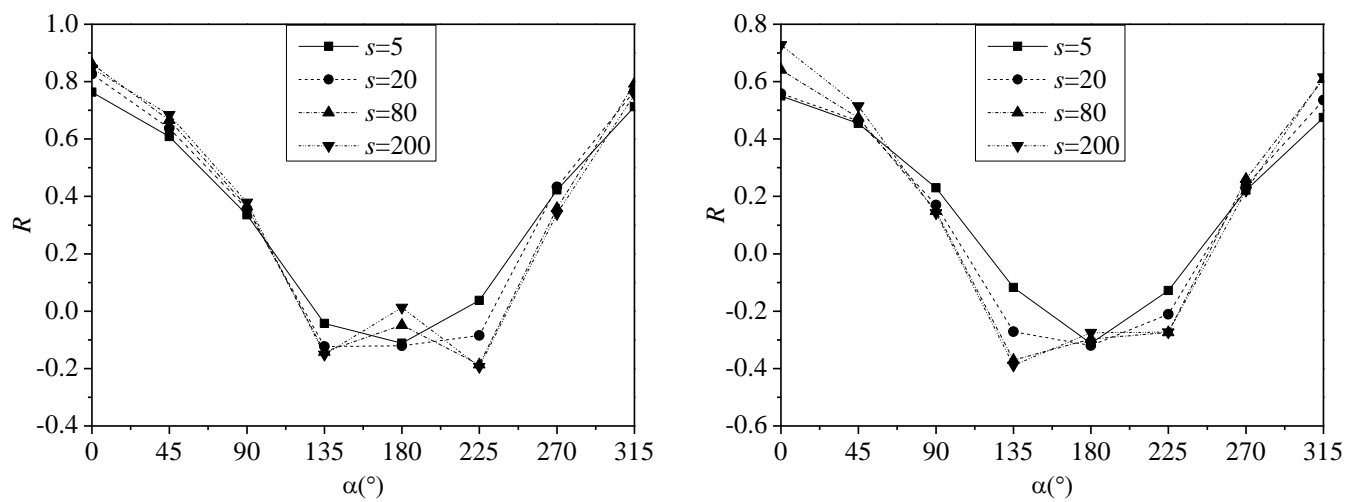

(a) $L=3.0 D, T_{p}=0.8 \mathrm{~s}, k_{p} a=1.26$
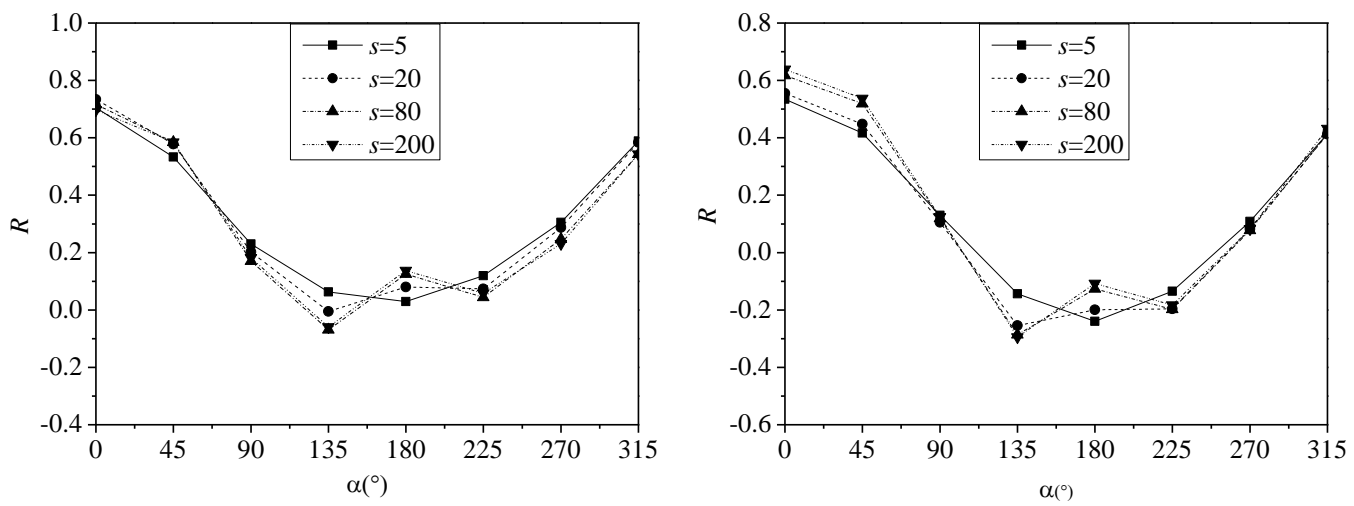

(b) $L=3.0 D, T_{p}=1.0 \mathrm{~s}, k_{p} a=0.83$

Fig. 15 The multi-directional wave run-up on four cylinders with $L=3.0 D$ for different directional distribution spreading parameter $s$ (The left part for the front cylinder, the right for the back cylinder)

\subsubsection{The multi-directional wave forces on cylinders}

Wave force is one of the most important parameters for the design of reliable 
offshore structures. In this part, the effect of the wave directionality on multi-directional wave forces is investigated.

Fig. 16 shows the multi-directional wave force on two cylinders in tandem as shown in Fig.8. In the figure, the wave force on a single cylinder is also presented for comparison. The figure shows that for the normal wave forces, as the width of wave directional spreading become wider (smaller $s$ ), the normal wave forces for the front and back cylinder tend to decrease slightly. For the transverse forces however, the tendency is opposite. The effect of the wave directionality on the transverse forces is more significant. Generally, as for the normal forces, the front cylinder always has a shielding effect on the back one. But for the transverse force, especially for the layout with a small gap between the two cylinders, it can be seen that the transverse force on the back cylinder are always larger than those on the front cylinder. This phenomenon is different for the results with unidirectional waves and should be paid much attention in real design.
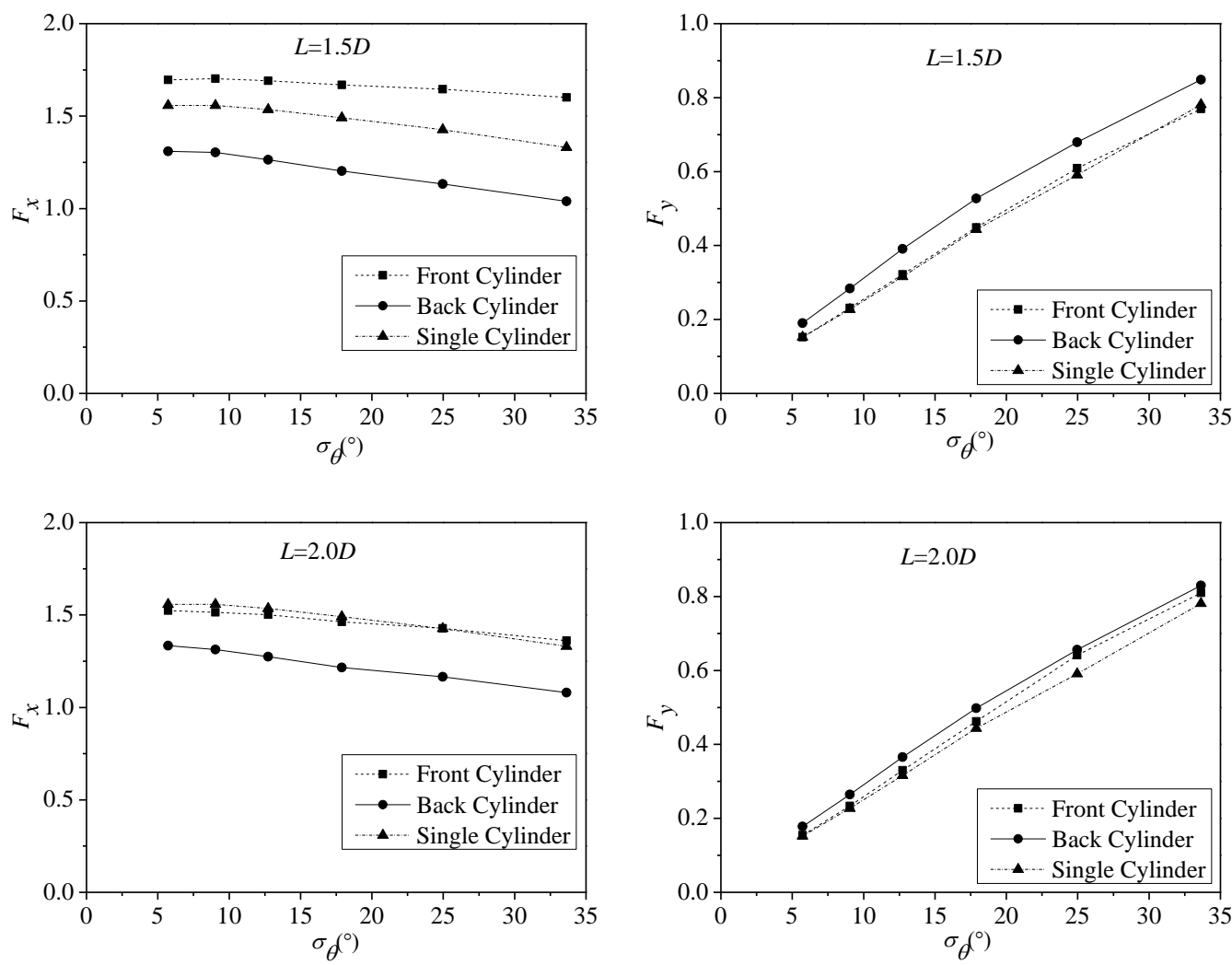

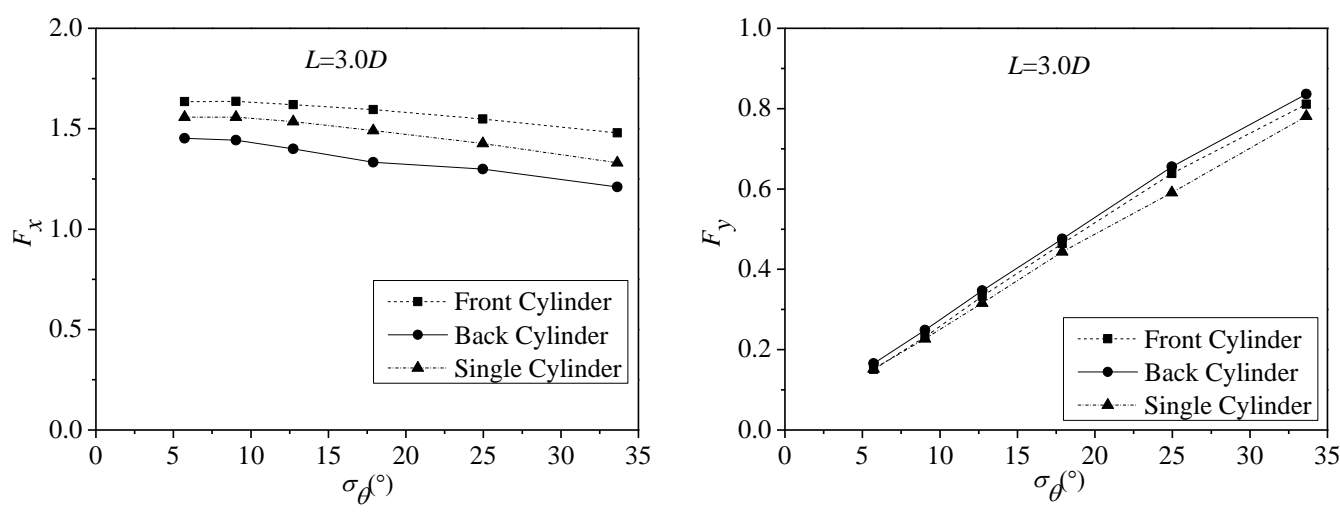

Fig.16 Multi-directional wave forces on two tandem cylinders $\left(T_{p}=0.8 \mathrm{~s}, k a=1.26\right.$, the left part for the normal force, the right part is the transverse force)

In order to further clarify the effect of wave directionality on the transverse force for the multi-directional wave interaction with an array of cylinders, two tandem cylinder arrays with 3 and 6 cylinders, respectively are considered. The diameter of the cylinders and the space between adjacent cylinders are keeping the same. Fig.17 shows the transverse force on each cylinder for the 3 cylinders and 6 cylinders cases. It is obvious that these results are similar to those described above, with the largest transverse force occurring on the last cylinder. The reason should be attributed to the properties of multi-directional waves. Multi-directional random waves are composed of different directional waves. For a long tandem cylinder array, when the waves propagate with the main direction along the tandem cylinders, the directional waves propagate from one side of the array to the other side. The cylinders will block the wave propagation. That will cause a non-uniformity of the waves on the two sides of the tandem cylinders, especially at the back part of the array.

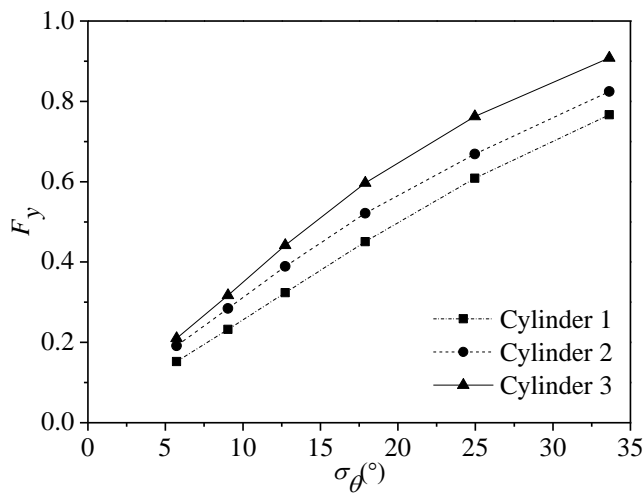

(a) 3 cylinders array

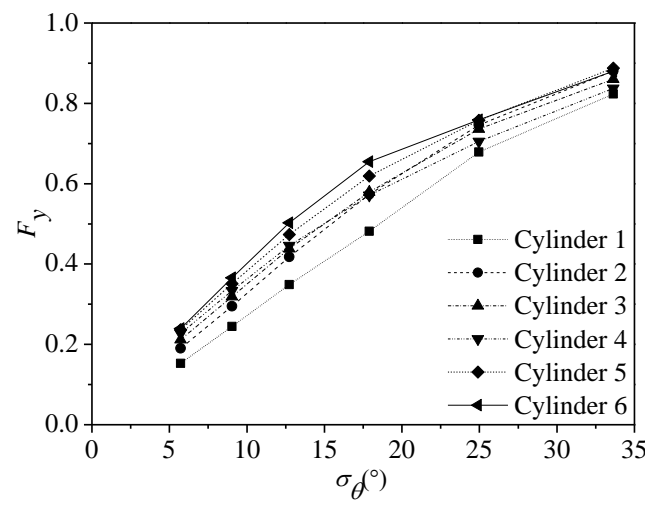

(b) 6 cylinders array

Fig.17 The transverse forces on the cylinders in tandem arrays with 3 and 6 cylinders

$$
\left(L=1.5 D, T_{p}=0.8 \mathrm{~s}, k a=1.26\right)
$$

Fig.18 gives the multi-directional wave force on a square array of cylinders (see 
Fig.4). As discussed above, the wave directionality has an obvious effect on wave forces, especially, on the transverse force. It can be seen that as the directional distribution becomes wider ( (smaller $s$ ), the transverse force $F_{y}$ increases significantly. For example, the transverse force on the front cylinders (Cylinder 1) for the wider directional distribution $\sigma_{\theta}=33.63(s=5)$ is around 1.6 times the transverse force for the narrower directional distribution $\sigma_{\theta}=5.72(s=200)$, whilst it is about 3 times larger for the back cylinders (Cylinder 4). Thus in real engineering design, the wave directionality should be considered since a unidirectional assumption may substantially underestimate the wave loading.

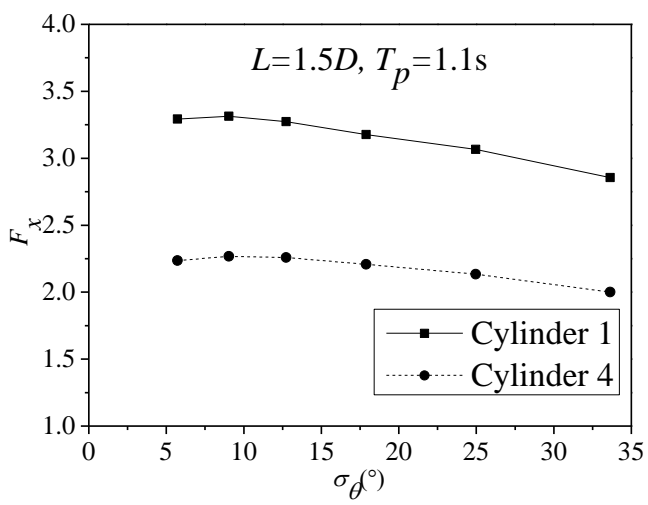

(a) the normal force

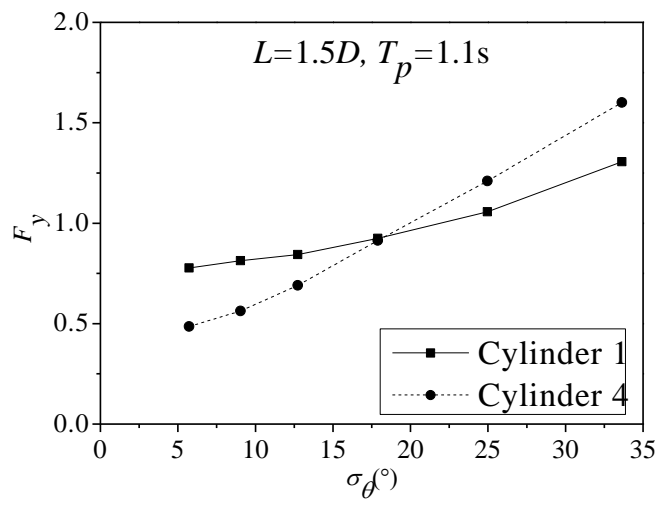

(b) the transverse force

Fig.18 Multi-directional wave forces on a square array of cylinder

\subsubsection{Near-trapping in multi-directional random wave condition}

Trapping and near-trapping by array of cylinders in regular waves has been investigated by some researchers. To show the effect of the wave directionality on the near-trapping by array of cylinders, the trapping and near-trapping by array of cylinders in multi-directional random waves are investigated in the present paper.

Fig.19 shows the layout for the square array of cylinders that the trapping and near-trapping might occur (the same as Evans and Porter, 1999). The water depth is $0.5 \mathrm{~m}$. Fig. 20 shows the normal and transverse force on the array with spacing $L=1.25 \mathrm{D}$ varying with $\mathrm{ka}$ under the regular wave condition. The forces are normalized with the normal regular wave force on an isolated cylinder. It can be seen that peak values for the normal and transverse forces occur at $k a=4.0875(T=0.44397 \mathrm{~s})$. The forces are about 55.3 and 54.7 times the force on an isolated cylinder for the normal force on cylinder 1 and cylinder 4, respectively and 54.6 times the forces on an isolated cylinder for the transverse force on cylinder 2 and cylinder 3 . This can only be due to a near-trapping wave at the wave number of $k a=4.0875$. 

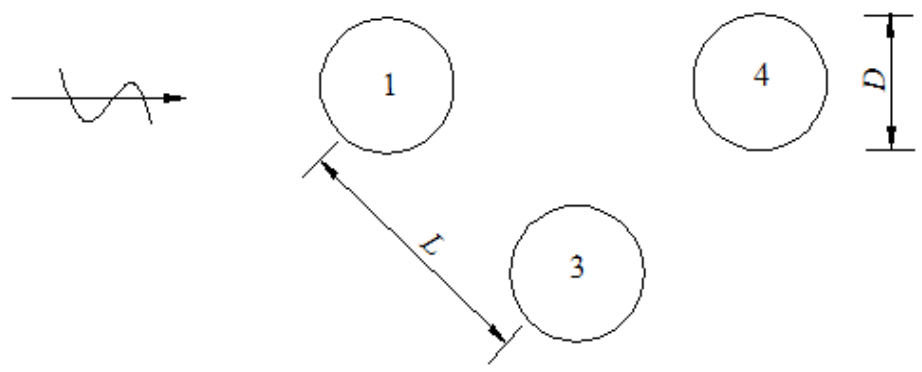

Fig. 19 Layout for the square array of cylinder

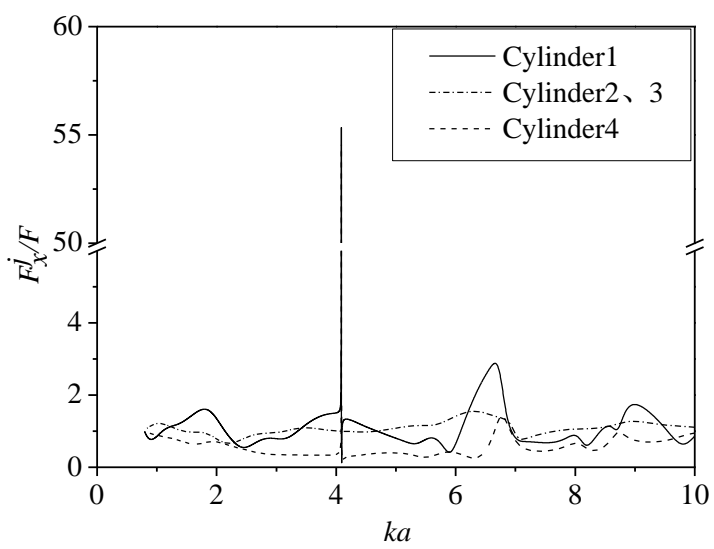

(a) the normal force

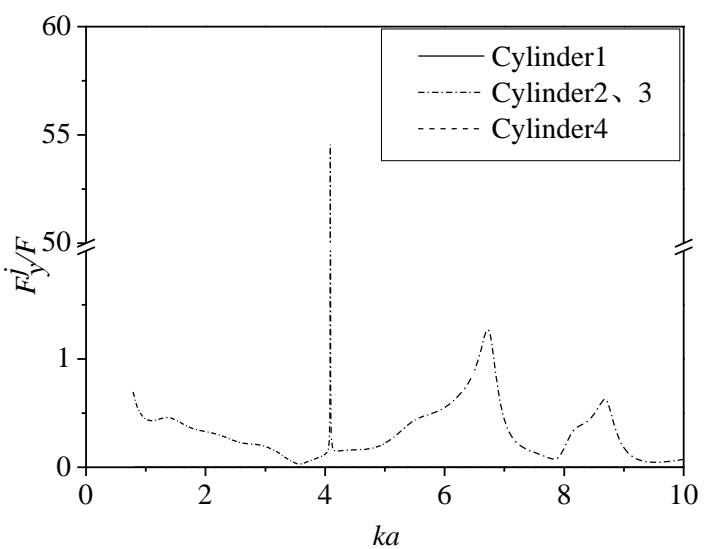

(b) the transverse force

Fig. 20 The wave forces on four cylinders against wave number $k a(H=0.04 \mathrm{~m}, F$ is the wave force on a single cylinder)

To investigate the possibility of the trapping and near-trapping by array of cylinders under the multi-directional random waves, multi-directional random wave interaction with the array shown in Fig. 19 with spacing $L=1.25 D$ are considered. In the calculation, the peak period $T_{p}=0.44397 \mathrm{~s}\left(k_{p} a=4.0875\right), H_{1 / 3}=0.04 \mathrm{~m}$ is used to be consistent with the above regular wave condition. The principal wave direction $\theta_{0}=0^{\circ}$. The energy of the incident wave is mainly distributed around the peak period and the principal wave direction. Also, during the simulation, the component waves are carefully selected to assure that the component wave with $k_{p} a=4.0875$ and the incident angle $\theta=0^{\circ}$ is included.

The variations of the maximum wave forces with the variance of the directional spreading are presented in Fig.21. Similarly, the forces are normalized with the normal regular force on an isolated cylinder. It can been seen that the normal forces on cylinder 1 and cylinder 4 and the transverse forces on cylinder 2 and cylinder 3 are 
bigger than the force on an isolated cylinder, it is similar as the regular results shown in Fig.20. That means the near-trapping also occurs in multidirectional waves. But the wave directionality has a definite effect on the phenomenon of the near-trapping. The near-trapping decreases with the variance of the wave directional spreading increasing. That means the wave directionality can restrain the occurrence of near-trapping. In addition, at $\sigma_{\theta}=0^{\circ}$, which means the unidirectional random wave, the near trapping is the most apparent. But the wave forces are much smaller than that in regular wave because of the effect of wave randomness.

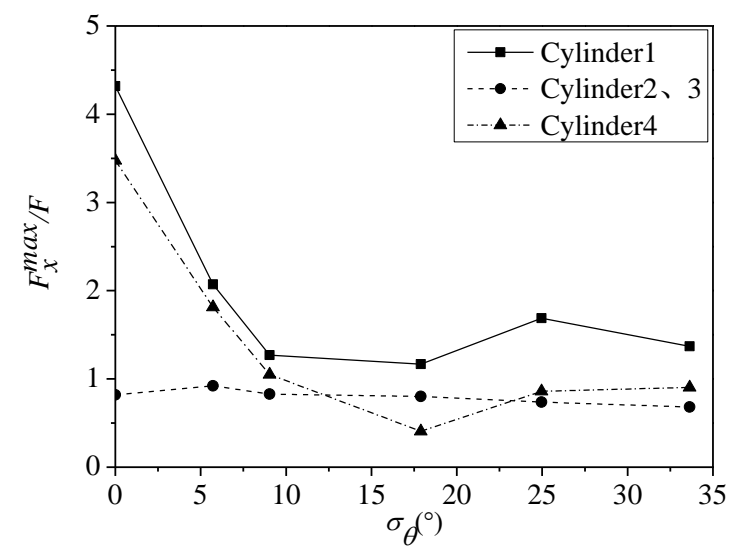

(a) normal force

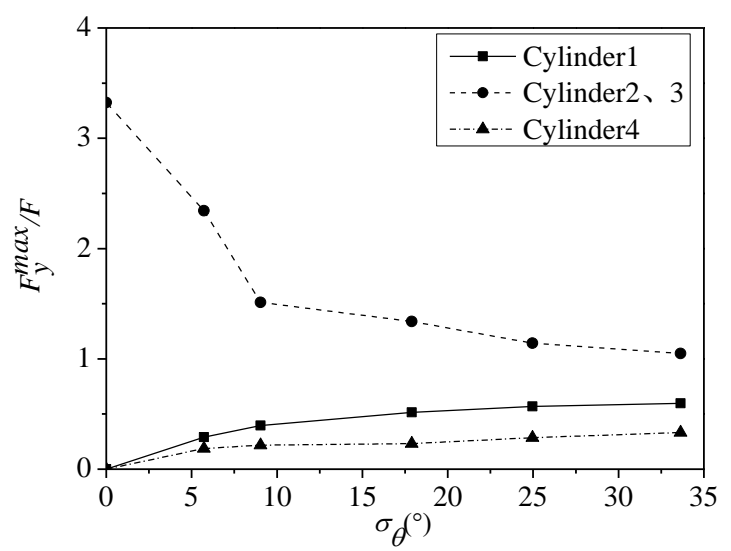

(b) transverse force

Fig.21 The ratio for the maximum wave force varying with the variance of the wave directional distribution $\left(H_{1 / 3}=0.04 \mathrm{~m}, T_{p}=0.44397 \mathrm{~s}, k_{p} a=4.0875\right)$ 


\section{Conclusions}

In the present paper, the multiple-cylinder diffraction solution is applied to multi-directional random wave interaction with several representative arrays of cylinders. The calculated results compare well with the related experimental results, and it was proved to be valid for the calculation for multi-directional wave action on arrays of cylinders. Generally, in the process of designing offshore structures, the standards are always based on unidirectional waves. In order to investigate real sea wave interaction with arrays of cylinders, a systematic set of calculations were made to study the effects of wave directionality on the wave run-up and wave forces on the cylinders. At last, the possibility of the near-trapping under the multi-directional random waves is investigated.

The effect of the wave directionality on the wave run-up depends on the position on the cylinder and the layout of the array. For the front cylinders, the wave run-up increases as $s$ becomes larger at the front parts, while it is opposite at the back part. But for the back cylinders, the wave run-up increases as the directional spreading parameter $s$ decreases. This means that the wave run-up for a multi-directional wave condition is larger than that for unidirectional waves.

A similar effect of the wave directionality is found for both the normal and transverse force on an array of cylinders compared with a single cylinder. The effect of wave directionality on the transverse force is more pronounced than on the normal force. As the standard deviation $\sigma_{\theta}$ increases, i.e., the wave directional distribution becomes wider, the transverse force $F_{y}$ increases significantly. Furthermore, it should be noted that the largest transverse force occurs on the last cylinder of a tandem array. This result is quite different from what is found in unidirectional waves, and should be paid much attention during the design of offshore structures. Generally, the normal force would be overstated based on the unidirectional waves, while the transverse force is underestimated. In the real sea condition, the waves are multi-directional, to forecast the wave force accurately and reasonably, especially for the transverse force, the wave directional distribution should be measured and considered.

When the near-trapping occurs, there would have very large force on cylinders, but the condition is strict. The possibility of the near-trapping under the multi-directional random waves is investigated. It is found that the near-trapping also occurs in multi-directional random wave conditions. But the wave directionality has a definite effect on the wave force. The narrower the wave directional distribution, the larger the wave force on special cylinder for the near-trapping. That means the wave directionality can restrain the occurrence of near-trapping in some extent.

\section{Acknowledgments}

This work was financially supported by the National Basic Research Program 
(Grant Nos. 2013CB036101 and 2011CB013703) and the National Natural Science Foundation of China (Grant Nos. 51221961). The first author would like to thank the China Scholarship Council (CSC) for financial support and the scholarship award.

\section{References}

Duclos G., Clément A.H., 2004. Wave propagation through arrays of unevenly spaced vertical piles. Ocean Engineering, 31(13), 1655-1668.

Evans D.V., Porter R., 1997. Near-trapping of waves by circular arrays of vertical cylinders. Applied Ocean Research, 19 (2), 83-99.

Evans D V, Porter R., 1999. Trapping and near-trapping by arrays of cylinders in waves[J]. Journal of Engineering Mathematics, 35(1-2): 149-179.

Goda, Y., 1999. A comparative review on the functional forms of directional wave spectrum. Coastal Engineering Journal, 41(1), 1-20.

Govaere, G., Silva, R. (2002). Directional Wave Transformation Induced by a Cylindrical Permeable Pile. In Ocean Wave Measurement and Analysis (2001). ASCE, 2002: 1763-1772.

Govaere, G., Silva, R. Maza, J., 1999. Wave kinematics around a protected cylindrical impermeable pile. Coastal Structures. Balkema, Rotterdam. 1:151-158.

Govaere, G., Silva, R. Salles, P., 2001. Wave Forces Acting on a Protected Impermeable Pile. Pacific Conference PACON 2001, San Francisco, USA (2001), 323-332.

Huang J.B., 2004. Nonlinear free surface action with an array of vertical cylinders. Acta Mechanica Sinica, 20(3), 247-262.

Ji, X.R., Liu, S.X, Li, J.X., 2013. Experimental research on the effects of the wave directionality on the wave run-up on a large cylinder. Proceedings of the 23rd (2013) International Offshore and Polar Engineering Conference, Anchorage, 616-621.

Ji, X.R., Liu, S.X, Li, J.X., Yang, Z.W., Jia, W., 2014. Numerical investigation of multi-directional random wave interaction with a large cylinder. Submitted to China Ocean Engineering.

Ji, X.R., Liu, S.X, Li, J.X., Jia W. 2015. Experimental investigation of the interaction of multi-directional irregular waves with a large cylinder. Ocean Engineering, 93, 64-73.

Kagemoto H., Yue D.K., 1986 Interactions among multiple three-dimensional bodies in water waves: an exact algebraic method. Journal of Fluid Mechanics, 166, 189-209.

Kagemoto H., Murai M., Fujii T., 2013. Second-order resonance among an array of two rows of vertical circular cylinders. Proceedings of 28th International Workshop on Water Waves and Floating Bodies, Marseille.

Kagemoto H., Murai M., Fujii T., 2014. Second-order resonance among an array of two rows of vertical circular cylinders-Comparisons of theoretical calculations 
and reality. Proceedings of 29th International Workshop on Water Waves and Floating Bodies, Osaka.

Kriebel, D.L., 1992. Nonlinear wave interaction with a vertical circular cylinder. Part II: Wave run-up. Ocean Engineering, 19(1), 75-99.

Kriebel, D.L., 1998. Nonlinear wave interaction with a vertical circular cylinder: Wave forces. Ocean Engineering, 25(7), 597-605.

Lee, H.S., Wang, K.H., Williams, A.N., 2007. A three-dimensional modeling of multi-directional random wave diffraction by rectangular submarine pits. Ocean Engineering, 34 (5-6), 665-675.

Li, J.X., Wang, Z.H., Liu, S.X., 2012. Experimental study of interactions between multi-directional focused wave and vertical circular cylinder. Part I: Wave run-up, Coastal Engineering, 64, 151-160.

Li, J., Wang, Z., Liu, S., 2014. Experimental study of interactions between multi-directional focused wave and vertical circular cylinder, part II: Wave force. Coastal Engineering, 83, 233-242.

Linton C.M., Evans D.V., 1990. The interaction of waves with an array of circular cylinders. Journal of Fluid Mechanics, 215, 549-569.

Liu, S.X., Sun, Z.B., Li, J.X., 2010. Numerical Calculation of Multi-directional Wave Run-up in Pile Group by a FEM Boussinesq Model. Proceedings of the 9th (2010) ISOPE Pacific/Asia Offshore Mechanics Symposium, Busan, 14-17.

Liu, S.X., Sun, Z.B., Li, J.X., 2012. An unstructured FEM model based on Boussinesq equations and its application to the calculation of multi-directional wave run-up in a cylinder group. Applied Mathematical Modelling, 36(9), 4146-4164.

Longuet-Higgins, M.S., Cartwright, D.E., Smith, N.D., 1963. Observations of the directional spectrum of sea waves using the motions of floating buoy. In Ocean Wave Spectra, Prentice-Hall Inc, Englewood Cliffs, N. J. USA, 111-136.

Ma Q.W., Wu G.X., Eatock Taylor R., 2001a. Finite element simulation of fully non-linear interaction between vertical cylinders and steep waves. Part 1. Methodology and numerical procedure. International Journal for Numerical Methods in Fluids, 36 (3), 265-285.

Ma Q.W., Wu G.X., Eatock Taylor R., 2001b. Finite element simulations of fully non-linear interaction between vertical cylinders and steep waves. Part 2. Numerical results and validation. International Journal for Numerical Methods in Fluids, 36(3), 287-308.

MacCamy, R., Fuchs, R.A., 1954. Wave forces on piles: a diffraction theory. Technical report 69, US Army Coastal Engineering Research Center, Beach Erosion Board Technical Memorandum, 1-17.

McIver P., Evans D.V., 1984. Approximation of wave forces on cylinder arrays. Applied Ocean Research, 6(2), 101-107.

Maniar H.D., Newman J.N., 1997. Wave diffraction by a long array of cylinders Journal of Fluid Mechanics, 339, 309-330. 
Maleniča S., Eatock Taylor R., Huang J.B.,1999. Second-order water wave diffraction by an array of vertical cylinders. Journal of Fluid Mechanics, 390,349-373.

Niedzwecki, J.M., Liagre, P.F. Borgman, L.E., 2001. Directional sea response of a mini-TLP. Proceedings of the 11th (2001) International Offshore and Polar Engineering Conference, Stavanger, 447-453.

Ohl C.O.G., Eatock Taylor R., Taylor P.H., Borthwick A.G.L., 2001a. Water wave diffraction by a cylinder array. Part 1. Regular waves. Journal of Fluid Mechanics, 442, 1-32.

Ohl C.O.G., Eatock Taylor R., Taylor P.H., Borthwick A.G.L., 2001b. Water wave diffraction by a cylinder array. Part 2. Iregular waves. Journal of Fluid Mechanics, 442, 33-66.

Silva, R., Govaere, G. Salles, P., 2003. Wave interaction with cylindrical porous piles. Ocean Engineering. 30 (14): 1719-1740.

Spring B.N., Monkmeyer P.L., 1974. Interaction of plane waves with vertical cylinders. Proceedings of 14th international conference on coastal engineering, Copenhagen, 1974, 1828-1845.

Swan C., Taylor P.H., Van Langen, H., 1997. Observations of wave-structure interaction for a multi-legged concrete platform. Applied Ocean Research, 19 (5-6), 309-327.

Wang C.Z., Wu G.X., 2010. Interactions between fully nonlinear water waves and cylinder arrays in a wave tank. Ocean Engineering, 37 (4), 400-417.

Yu, Y.X., Liu, S.X., Li L., 1991. Numerical simulation of multi-directional random seas. Proceedings of the 1st International Offshore and Polar Engineering Conference, 26-32.

Yu, Y.X., Zhang, N.C., Zhao, Q., 1996. Wave Actions on a Vertical Cylinder in Multi-Directional Random Waves. Proceedings of 25th Conference on Coastal Engineering, Orlando, 415-428.

Zhao, F., Kinoshita, T., Bao, W., Itakura, H.,2010. Wave fields diffracted by an array of porous circular cylinders. Proceedings of the ASME 29th International Conference on Ocean, Offshore and Arctic Engineering, 65-74. 